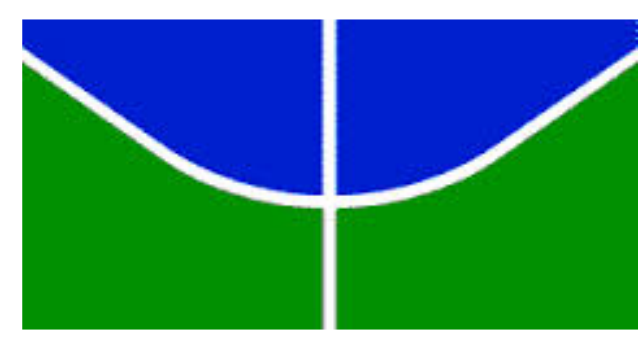

UNIVERSIDADE DE BRASÍLIA

FACULDADE DE EDUCAÇÃO

ALCANCE E LIMITES DA PEDAGOGIA DE GRUPOS REALIZADA COM ADOLESCENTES EM CUMPRIMENTO DE MEDIDAS SOCIOEDUCATIVAS NO DISTRITO FEDERAL

AURÉLIO LANDIM ALBUQUERQUE

BRASÍLIA DF 
Monografia apresentada a Faculdade de Educação com requisito parcial para obtenção do título de graduação em Pedagogia da Universidade de Brasília - UnB.

Orientador: Prof. Dr. Paulo Sergio de Andrade Bareicha

Universidade de Brasília (UnB)

Faculdade de Educação

BRASÍLIA - DF 2017 


\title{
ALCANCE E LIMITES DA PEDAGOGIA DE GRUPOS REALIZADA COM ADOLESCENTES EM CUMPRIMENTO DE MEDIDAS SOCIOEDUCATIVAS NO DISTRITO FEDERAL
}

Monografia apresentada à Faculdade de Educação, como requisito parcial à obtenção do título de Graduação do Curso de Pedagogia da Universidade de Brasília, apreciada e aprovada em 07 de julho de 2017 pela banca examinadora composta por:

Prof. Dr. Paulo Sérgio de Andrade Bareicha (Orientador)

Universidade de Brasília

Prof. Dr. José Luiz Villar Mella

Universidade de Brasília

\author{
Nirce Barbosa Castro Ferreira \\ Doutoranda em Educação - PPGE / FE \\ Universidade de Brasília
}

BRASÍLIA DF 
Aos meus pais, esposa e familiares 


\section{AGRADECIMENTOS}

Inicialmente agradeço a Deus por me possibilitar concluir o curso de Pedagogia. O período que estive na Faculdade de Educação me possibilitou conhecer pessoas fantásticas e adquirir aprendizados que levarei para toda a vida.

A minha querida esposa Gizelma, que com paciência, amor, carinho e companheirismo, sempre esteve ao meu lado me apoiando, me dando forças e me lembrando constantemente que sou capaz. Te amo!

Aos meus amados pais, Ivanete e Francisco (Frantonio), por terem me incentivado aos estudos, pelo carinho que constantemente tiveram, pela dedicação de anos. Verdadeiros anjos em minha vida. Obrigado por tudo!

Aos meus irmãos Flaésio (irmão gêmeo) e Sanclé (irmão caçula) pela constante força e confiança.

Aos professores que tive a oportunidade de conhecer e aprender, especialmente ao Professor Paulo Sergio de Andrade Bareicha, que me acompanhou nesse árduo processo e que também faz parte dessa conquista.

Aos colegas estudantes com quem convivi e compartilhei experiências, ideias nessa bela jornada ao conhecimento.

Agradeço também a Vara de Execução de Medidas Socioeducativas - VEMSE e a Secretaria de Estado de Políticas para Crianças, Adolescentes e Juventude do Distrito Federal - SECRIANÇA pela autorização para a realização da pesquisa.

Aos servidores da SECRIANÇA pela receptividade e pela disponibilidade em participar voluntariamente da pesquisa.

A todos o meu muito obrigado! 


\section{RESUMO}

Esse trabalho trata da temática de Pedagogia de Grupos aplicada a adolescentes em cumprimento de medidas socioeducativas no Distrito Federal. A realização da pesquisa emergiu a partir da necessidade de identificar com maior clareza os alcances e as limitações encontradas nas práticas de grupos socioeducativos realizadas junto a adolescentes em cumprimento de medidas socioeducativas, sejam em meio aberto (Liberdade Assistida e Prestação de Serviços à Comunidade) em Semiliberdade ou em Internação. A partir da contextualização do referencial teórico da pesquisa foi possível abordar as legislações que tratam das medidas socioeducativas aplicadas a adolescentes que pratiquem atos infracionais e conceitos teóricos metodológicos de autores que abordam em suas obras literárias a temática socioeducação, e também as práticas pedagógicas em diversos espaços e contextos educativos. Foram realizadas entrevistas semiestruturadas junto a servidores - Especialistas Socioeducativos e temporários (Pedagogos, Psicólogos e Assistentes Sociais), profissionais vinculados à Secretaria de Estado de Políticas para Crianças, Adolescentes e Juventude do Distrito Federal que atuam diretamente com os adolescentes, nas respectivas medidas socioeducativas. Para a análise dos dados coletados optou-se pela metodologia de Análise de Conteúdo. Com a realização da pesquisa foi possível identificar alguns alcances dos grupos socioeducativos, como por exemplo a interação social, compartilhar histórias de vida e a possibilidade de adquirir novos saberes. Quanto às limitações, ressaltamos a escassez de servidores, questões de logística das unidades e a ausência de métodos avaliativos institucionalizados que permitam mensurar os ganhos e as limitações das práticas pedagógicas adotadas e possibilitar repensar de modo assertivo novas estratégias. Observou-se também a necessidade de as Universidades estarem mais próximas das práticas interventivas, para assim contribuírem sistematicamente por meio dos eixos de ensino, pesquisa e extensão com as práticas pedagógicas de grupos na socioeducação.

Palavras-chave: Socioeducação, Grupos Socioeducativos, Práticas pedagógicas 


\begin{abstract}
The present study aims the theme of Pedagogy applied to group works with adolescents and juvenile offenders involved in the context of crimes in the city of Brasília, Brazil. The research intends to identify more clearly the benefits and limitations of the group work methodology as carried out with adolescents in probation or imprisoned. The methodology used approaches literature and legislation reviews regards to juvenile offenders and justice measures applied in their cases. It also discusses the analysis of recognized authors on the theme of socio and educational practices on several contexts, in and outside schools. Additionally the research brings data gathered through interviewing educational system of juvenile offenders' workers (Pedagogues, Social Workers and Psychologists). Once the data was collected it was analyzed using the method of content analysis. The results show that the group works with these adolescents improves social interaction; life stories share experience and knowledge acquisition. The study points out as limitations to the methodology of group work the scarcity of workers, poor logistics and lack of proper evaluation programs. It becomes clear as an additional result how necessary is the contribution of University researchers on planning and building more effective group work practices in the context of the work with juvenile and young offenders.
\end{abstract}

Key words: Socioeducation, Socio-educational groups, pedagogical practices 


\section{LISTA DE TABELAS}

TABELA 1 - Quantitativo de profissionais Especialistas Socioeducativos - ESOCIO e temporários, lotados nas Unidades de Atendimento em Meio Aberto - UAMA..........26

TABELA 2 - Quantitativo de profissionais Especialistas Socioeducativos - ESOCIO e temporários, lotados nas Unidades de Semiliberdade.

TABELA 3 - Quantitativo de profissionais Especialistas Socioeducativos - ESOCIO e temporários, lotados nas Gerências Sociopsicopedagógicas, das Unidades de

Internação.

TABELA 4 - Cronograma de Atividades 39

TABELA 5 - Quantitativo de profissionais entrevistados por cargos e unidades......41 


\section{LISTA DE QUADROS}

QUADRO 1 - Respostas por categorias e na ordem decrescente de repetições dos entrevistados que atuam em medida socioeducativa de Internação. .42

QUADRO 2 - Respostas por categorias e na ordem decrescente de repetições dos entrevistados que atuam em medida socioeducativa de Semiliberdade.

QUADRO 3 - Respostas por categorias na ordem decrescente de repetições dos entrevistados que atuam em medida socioeducativa de Liberdade Assistida e Prestação de Serviços à Comunidade. 


\section{LISTA DE FIGURAS}

FIGURA 1 - Características do Grupo Socioeducativo - GS segundo os

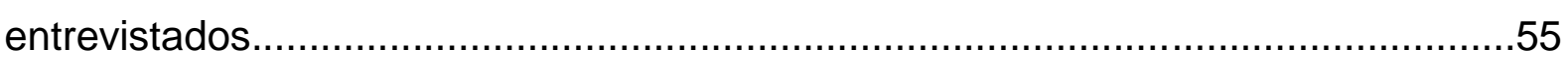

FIGURA 2 - Sugestões para conteúdos e práticas na Universidade em socioeducação a serem trabalhados nos eixos educação, pesquisa e extensão 


\section{LISTA DE SIGLAS E ABREVIATURAS}

$\begin{array}{ll}\text { CNE } & \text { Conselho Nacional de Educação } \\ \text { DCA } & \text { Delegacia da Criança e do Adolescente } \\ \text { ECA } & \text { Estatuto da Criança e do Adolescente } \\ \text { ESOCIO } & \text { Especialista Socioeducativo } \\ \text { GF } & \text { Grupo de Famílias } \\ \text { GS } & \text { Grupo Socioeducativo } \\ \text { LA } & \text { Liberdade Assistida } \\ \text { MPTFD } & \text { Ministério Público do Distrito Federal e Territórios } \\ \text { NAI } & \text { Núcleo de Atendimento Integrado } \\ \text { PDASE } & \text { Plano Decenal de Atendimento Socioeducativo } \\ \text { PSC } & \text { Prestação de Serviços à Comunidade } \\ \text { SECRIANÇA } & \text { Secretaria de Estado de Políticas para Crianças Adolescentes e } \\ & \text { Juventude do Distrito Federal } \\ \text { SEDESTMIDH } & \text { Secretaria de Estado de Trabalho, Desenvolvimento Social, } \\ & \text { Mulheres, Igualdade Racial e Direitos Humanos do Distrito Federal } \\ \text { SINASE } & \text { Sistema Nacional de Atendimento Socioeducativo } \\ \text { SUBSIS } & \text { Subsecretaria do Sistema Socioeducativo } \\ \text { UAMA } & \text { Unidade de Atendimento em Meio Aberto } \\ \text { UAI } & \text { Unidade de Atendimento Inicial } \\ \text { UIBRA } & \text { Unidade de internação de Brazlândia } \\ \text { UIP } & \text { Unidade de Internação de Planaltina } \\ \text { UISM } & \text { Unidade de Internação de Santa Maria } \\ \text { UISS } & \text { Unidade de Internação de São Sebastião } \\ \text { UNIRE } & \text { Unidade de Internação do Recanto das Emas } \\ \text { VEMSE } & \text { Vara de Execução de Medidas Socioeducativas }\end{array}$




\section{SUMÁRIO}

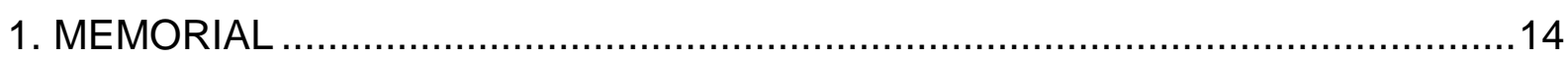

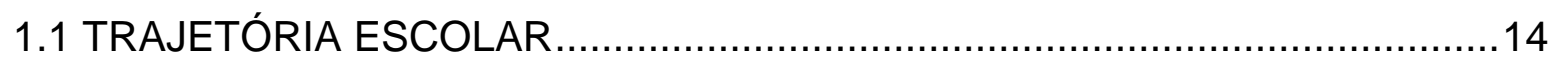

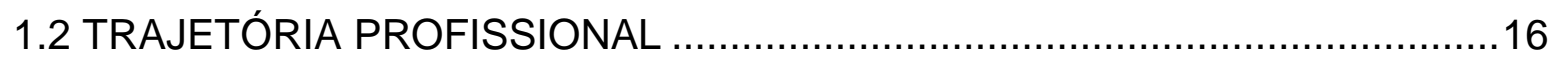

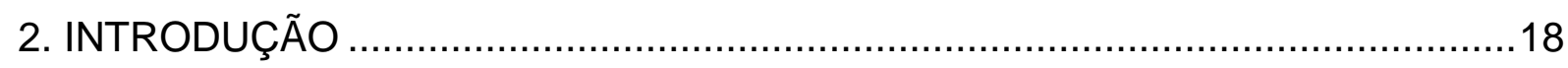

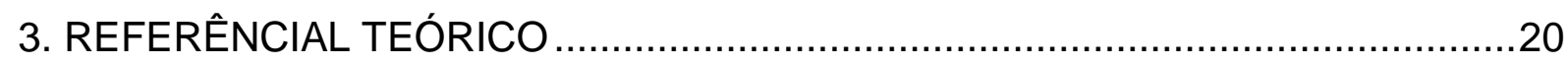

3.1 A LEGISLAÇÃO E AS MEDIDAS SOCIOEDICATIVAS................................20

3.2 CAMINHOS DO ADOLESCENTE INFRATOR NO SISTEMA

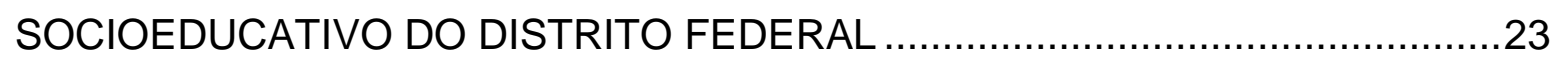

3.3 LEVANTAMENTO DO QUANTITATIVO DE ESPECIALISTAS

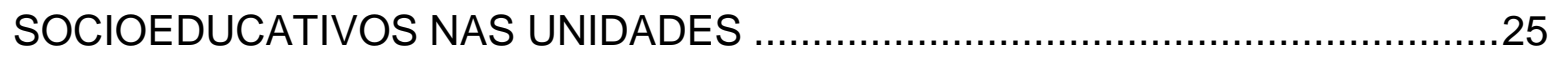

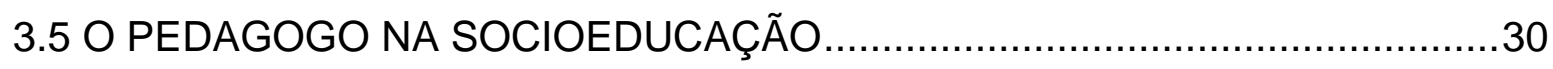

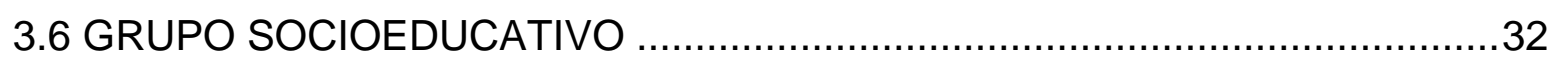

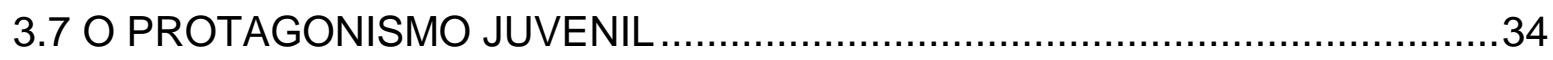

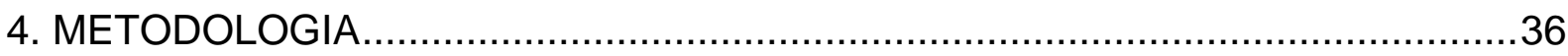

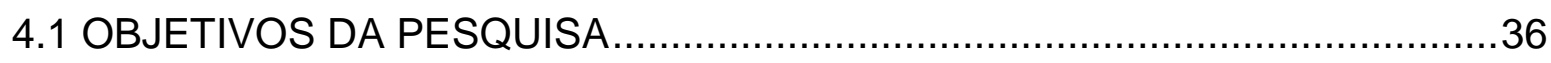

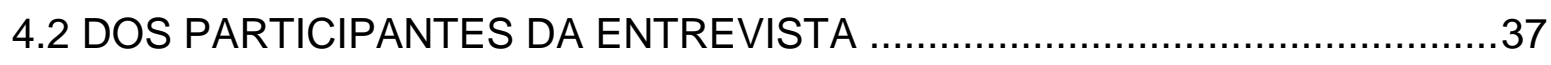

4.3 PROCEDIMENTO DE COLETA E REGISTRO DE DADOS .............................37

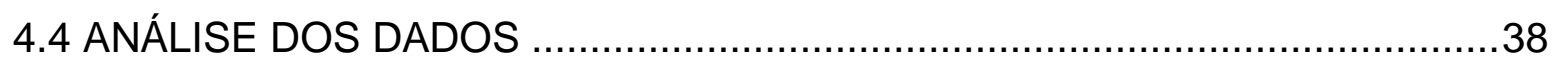

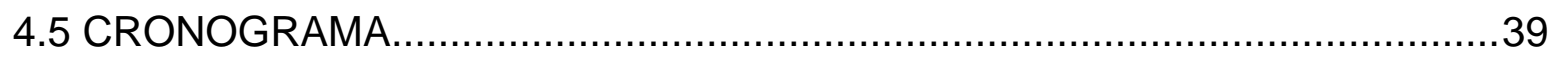

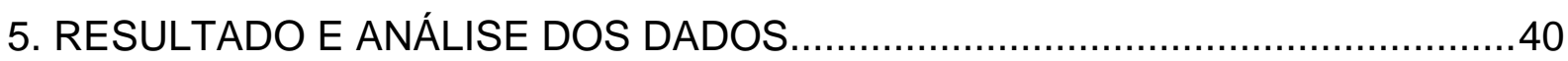

5.1 CARACTERIZAÇÃO DOS ENTREVISTADOS …......................................40

5.2 GRUPOS SOCIOEDUCATIVOS - INTERNAÇÃO …..................................41

5.3 GRUPOS SOCIOEDUCATIVOS - SEMILIBERDADE...................................45

5.4 GRUPOS SOCIOEDUCATIVOS - LIBERDADE ASSISTIDA E PRESTAÇÃO

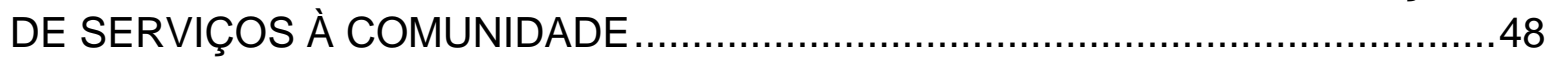

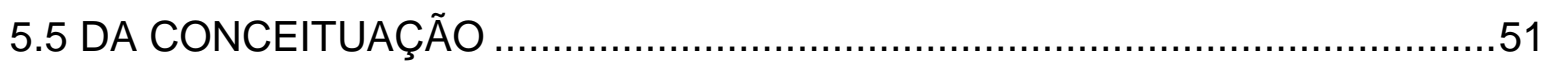

5.5.1 DOS REFERENCIAS TEÓRICO-METODOLÓGICOS ..............................51

5.5.1.1 PARTICIPANTES PEDAGOGOS ……................................................

5.5.1.1 PARTICIPANTES DEMAIS ESPECIALISTAS ..................................52

5.5.2 COMO OS PARTICIPANTES DEFINEM GRUPO SOCIOEDUCATIVO....53

5.5.3 SUGESTÕES PARA A UNIVERSIDADE.............................................56

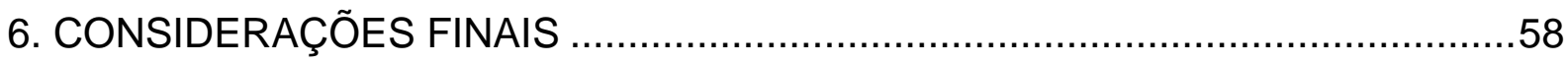




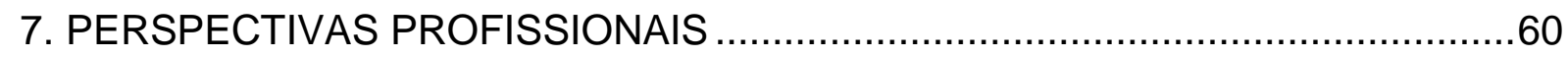

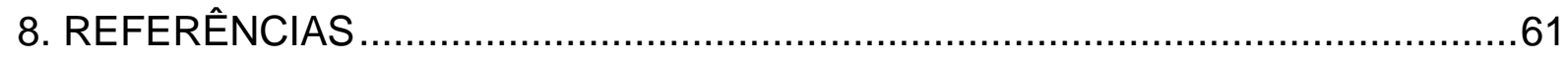

APÊNDICES

APENDICE A - ROTEIRO DE ENTREVISTA SEMIESTRUTURADO PARA OS

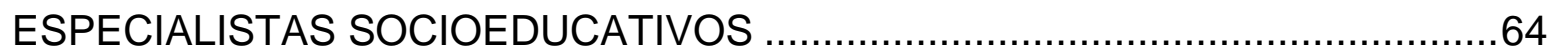

APENDICE B - TERMO DE CONSENTIMENTO LIVRE E ESCLARECIDO..........65

APENDICE C - SOLICITAÇÃO DE AUTORIZAÇÃO JUDICIAL ...........................66 


\section{MEMORIAL}

Eu me chamo Aurélio Landim Albuquerque, tenho 35 anos de idade, nasci na região administrativa de Planaltina DF, filho de uma comerciante e um psicólogo. Tenho um irmão gêmeo idêntico e um caçula, quatro anos mais novo. Cresci dentro do comércio dos meus pais, inicialmente um armarinho e posteriormente uma loja de roupas, acessórios e calçados. Conhecia quase todos os clientes e comerciantes das proximidades.

O convívio familiar sempre foi tranquilo, pautado no respeito e no diálogo. Sempre fui muito tímido e participava de quase tudo junto do meu irmão. Durante a infância gostava muito de brincar com meus primos e de passar as férias com meus avós na chácara deles, localizada no núcleo rural de Planaltina DF.

Passava bastante tempo na frente da televisão. Gostava muito de filmes, desenhos e seriados, como também de ir ao cinema.

\subsection{TRAJETÓRIA ESCOLAR}

Comecei minha trajetória escolar em 1986, aos cinco anos de idade. Lembro do primeiro dia de aula com detalhes. Meu pai nos deixou, meu irmão e eu, na Escola Adventista de Planaltina DF, na época era bem conceituada na cidade. O primeiro dia não foi muito bom, meu pai saiu discretamente, sem que percebêssemos. Aí o choro foi grande. Coube a professora nos acalmar. Não lembro bem o nome dela, mas recordo que foi atenciosa e conseguiu nos tranquilizar. Os dias seguintes foram melhores, conseguimos nos adaptar à nova realidade e as novas rotinas.

Durante o tempo que estudei na Escola Adventista tive a oportunidade de fazer muitos amigos e aprender bastante. Permaneci no colégio durante cinco anos, que foram da pré escola até a antiga terceira série do ensino fundamental.

No ano seguinte 1990, iniciamos a quarta série do ensino fundamental em uma escola pública de Planaltina. Era a Escola Classe 09 de Planaltina DF, localizada no Buritis II. Começamos a estudar lá por ser perto de nossa casa e devido ao fato de 
uma tia paterna ser professora da escola e acabou indicando aos meus pais, acabamos ficando um ano na escola. Houve momentos bons, outros não muito bons. Porém, durante o ano que permanecemos aprendemos com nossos acertos erros. Como era uma Escola Classe, só tinha até a antiga quarta série.

Em 1991, iniciamos a antiga quinta série do ensino fundamental no Centro de Ensino Fundamental 08 de Planaltina DF, localizado entre as quadras 03 e 04 da Vila Buritis. Também foi um choque de realidades, começamos a ter um professor por disciplina. Lembro que fiquei muito empolgado, pois a partir desse ano podia usar canetas, e não somente lápis. O ano passou rápido. Meu irmão acabou reprovando na disciplina de Português. Foi só até aí que estudamos juntos.

No início de 1992, mudei novamente de escola. Fui para o Centro de Ensino Fundamental 02 de Planaltina DF, localizada no Setor Tradicional e popularmente conhecida como "Paroquial". Comecei a sexta série do ensino fundamental, enquanto meu irmão cursava a quinta série. Por lá fiquei durante dois anos.

Em 1995 iniciei a oitava série no atual Centro de Ensino Médio 02 de Planaltina. Era o último ano que teria uma série do ensino fundamental, pois no ano seguinte seria apenas séries do ensino médio, na época chamávamos de "científico".

Em 1996 ingressei no ensino médio. Me senti muito feliz, foi uma mudança de fase, uma barreira a menos, resultado de um caminho percorrido com esforço e dedicação. Estava começando o Programa de Avaliação Seriada - PAS, da Universidade de Brasília, porém não cheguei a participar.

O ensino médio foi uma boa experiência, com muitas atividades coletivas, 0 que possibilitou aprender muito com professores e colegas de classe. Momentos que vou levar para a vida toda com saudades. Em 1998 concluí o ensino médio, o que foi uma grande conquista. Estava a um passo do começar a faculdade.

Em 1999 eu me mudei para o município de Unaí MG para iniciar o curso superior de Tecnologia em Processamento de Dados na Faculdade de Ciências e Tecnologia de Unaí - FACTU. Morei na casa de uma senhora, que um médico amigo dos meus pais indicou, pois não conhecia ninguém na cidade e tinha apenas 17 anos. Fiquei apenas um ano em Unaí, porém um dos melhores anos da minha vida. 
No ano seguinte 2000, fui transferido para a Uniplan da Asa Sul. Em 2001 comecei a trabalhar em um Banco privado, o que foi outra grande conquista, pois nunca tinha sequer estagiado. Em 2002, conclui a graduação de Tecnólogo em Processamento de Dados.

Em 2009, conclui outra graduação, dessa vez licenciatura em Computação pela Faculdade Michelangelo. Neste período tive a oportunidade de concluir uma especialização em Comportamento Organizacional e Gestão de Pessoas, pela Escola Superior Aberta do Brasil - ESAB.

\subsection{TRAJETÓRIA PROFISSIONAL}

Em 2010, após dez anos de trabalho em uma instituição bancária, no qual o último cargo exercido foi o de Instrutor do Departamento de Treinamento, onde ministrava cursos comportamentais, motivacionais, de produtos e operações bancárias para os funcionários da instituição e de seguros para corretores, passei no concurso da Secretaria de Estado de Desenvolvimento Social e Transferência de Renda do Distrito Federal - SEDEST para o cargo de Educador Social, onde trabalhei nos Centros de Convivência, que executam o Serviço de Convivência e Fortalecimento de Vínculos - SCFV ${ }^{1}$, da Proteção Social Básica

Em 2014, eu fui redistribuído para a Secretaria da Criança, atual Secretaria de Estado de Políticas para Crianças, Adolescente e Juventude do Distrito Federal. Comecei atuando em uma Unidade de Internação que executa medida socioeducativa de internação estrita para adolescentes, conforme previsto no Estatuto da Criança e do Adolescente - ECA e no Sistema Nacional de Atendimento Socioeducativo Sinase. Atuava em oficinas profissionalizantes, no atendimento aos adolescentes e em atividades em grupos que tinham como eixo norteador o "Protagonismo Juvenil". Essa foi a principal motivação para a escolha da temática do meu trabalho de conclusão de curso.

\footnotetext{
${ }^{1}$ Trata-se do Serviço de Convivência e Fortalecimento de Vínculos - SCFV: Serviço da Proteção Social Básica, conforme descrito na Resolução № 109, de 11 de novembro de 2009 que aprovou a Tipificação Nacional dos Serviços Socioassistenciais.
} 
Em 2015, participei do vestibular de segunda graduação para o curso de Pedagogia da Universidade de Brasília, as aulas começaram no segundo período de 2015. Atualmente trabalho na Secretaria de Estado de Políticas para Crianças, Adolescentes e Juventude do DF e sou estudante do curso de licenciatura em Pedagogia. Neste momento me deparo com muitos desafios e descobertas, que se revelam uma oportunidade de conhecer pessoas e internalizar novos aprendizados e com isso aperfeiçoar cada vez mais minha prática profissional. 


\section{INTRODUÇÃO}

As possibilidades de atuação do pedagogo em diversos espaços educativos, nos faz refletir a salutar importância e necessidade da pedagogia ocupar esses territórios e contribuir com o processo educativo em todos seus aspectos. A exemplo podemos citar as práticas e teorias da Pedagogia de Grupos realizadas com adolescentes em cumprimento de medidas socioeducativas no Distrito Federal.

A realização da pesquisa na área de socioeducação surgiu devido o interesse do pesquisador em identificar com maior clareza os benefícios e dificuldades encontradas nas práticas de grupos socioeducativos, e em provocar uma reflexão crítica sobre os métodos pedagógicos adotados e a necessidade das Universidades se apropriarem mais da temática socioeducativa, bem como da comunidade cientifica estar mais próxima da prática interventiva e da comunidade.

A pesquisa busca identificar o alcance e os limites da Pedagogia de Grupos realizados com adolescentes em cumprimento de medidas socioeducativas, sejam em meio aberto (Liberdade Assistida e Prestação de Serviços à Comunidade) em Semiliberdade ou em Internação.

Iniciamos a descrição desse trabalho, com o memorial educativo, contendo breve relato da trajetória escolar do pesquisador. Em seguida inicia-se a contextualização a partir do referencial teórico da pesquisa sendo possível abordar as legislações que tratam das medidas socioeducativas aplicadas a adolescentes que pratiquem atos infracionais e conceitos teóricos metodológicos de alguns autores que abordam em suas obras literárias a temática socioeducação e as práticas pedagógicas em diversos espaços e contextos educativos.

A metodologia adotada para o desenvolvimento da pesquisa é de natureza qualitativa. Para a coleta de dados, foram realizadas entrevistas semiestruturadas, com apoio do instrumental Roteiro de Entrevista, junto a 30 (trinta) servidores especialistas socioeducativos, especificamente pedagogos, psicólogos e assistentes sociais da Secretaria de Estado de Políticas para Crianças, Adolescentes e Juventude do Distrito Federal, que atuam diretamente com adolescentes em cumprimento de medidas socioeducativas, nas Unidades de Atendimento em Meio Aberto (UAMA), nas Unidades de Semiliberdade e nas Unidades de Internação. 
Durante as entrevistas foram abordadas questões relacionadas a organização dos atendimentos em grupo, as temáticas abordadas, aos critérios de avaliação e a conceituação. Após as entrevistas, as informações coletadas foram transcritas para assim iniciar a análise dos dados. A metodologia utilizada para a análise qualitativa dos dados coletados foi a Análise de Conteúdo, sendo adotado como referencial teórico Bardin (2010).

A questão norteadora dessa pesquisa visa identificar: Como são organizadas as práticas educativas de grupo no contexto das medidas socioeducativas (SINASE) no Distrito Federal?

Com a pesquisa pretendemos contribuir para o desenvolvimento de novas práticas e estratégias destinadas aos grupos socioeducativos aplicados junto a adolescentes que pratiquem ato infracional e propor a comunidade cientifica mais aproximação e contribuições na área da socioeducação. 


\section{REFERÊNCIAL TEÓRICO}

\subsection{A LEGISLAÇÃO E AS MEDIDAS SOCIOEDICATIVAS.}

Existem diversas leis que garantem direitos ao público adolescente, que determinam e regulamentam a aplicação medidas socioeducativas destinadas a adolescentes que cometem a pratica de atos infracionais análogos a crimes ou contravenção penal. Veremos nos próximos subcapítulos como a legislação define o público adolescente e regulamenta as medidas socioeducativas.

Em junho de 1990 foi promulgada a lei $n \div$. 8.069 que trata do Estatuto da Criança e do Adolescente - ECA, revogando integralmente, por meio de seu Artigo no. 267 o extinto "Código de Menores". O Estatuto prevê a proteção integral e a garantia de direitos fundamentais, medidas de proteção, como também define ato infracional praticado por adolescente e as disposições gerais das Medidas Socioeducativas aplicáveis a esse público.

No que tange a aplicação das medidas, o Estatuto define como adolescente a pessoa que se encontra na faixa etária entre doze e dezoito anos de idade. (BRASIL, 1990).

Quanto ao ato infracional, trata-se de conduta descrita como crime ou contravenção penal, sendo que adolescente não comete crime, e sim ato infracional análogo a crime ou contravenção penal. Ao adolescente que pratique ato infracional estão previstas as medidas socioeducativas. (BRASIL, 1990).

O Estatuto da Criança e do Adolescente determina as medidas aplicáveis a adolescentes que pratiquem ato infracional, em seu Artigo oㅡ 112:

Art. 112. Verificada a prática de ato infracional, a autoridade competente poderá aplicar ao adolescente as seguintes medidas:

I - advertência;

II - obrigação de reparar o dano;

III - prestação de serviços à comunidade;

IV - Liberdade assistida;

$V$ - inserção em regime de semiliberdade;

VI - internação em estabelecimento educacional;

VII - qualquer uma das previstas no art. 101, I a VI.

$\S 1$ ㅇ A medida aplicada ao adolescente levará em conta a sua capacidade de cumpri-la, as circunstâncias e a gravidade da infração. [...] (BRASIL, 1990, p. 99). 
As medidas previstas na referida lei, possuem objetivos prioritariamente pedagógicos, e visam a reintegração social do adolescente, a partir de propostas que possibilitem ambientes educativos, restaurativos, a autorreflexão, repensar comportamentos e escolhas, desenvolver o senso crítico, favorecer o protagonismo e o empoderamento social do adolescente, como também garantir direitos e reforçar fatores de proteção. (DISTRITO FEDERAL, 2016a)

Segundo Saliba:

O princípio norteador do Estatuto é a ação pedagógica e educativa, uma vez que todas as medidas previstas devem prever a reeducação e a prevenção, a fim de estabelecer um novo padrão de comportamento e conduta ao infrator. Em todas as medidas ressalta-se o caráter educativo, a fim de promover a ruptura entre a prática de delitos e um novo projeto de vida do adolescente. (SALIBA, 2006, p.88).

Ao que concerne as características das citadas medidas socioeducativas previstas no ECA destinada ao adolescente que pratique ato infracional, Saliba (2006) as descrevem de acordo com a ordem no Artigo 112 da citada lei, sendo a primeira a advertência, aviso verbal, assinada a termo. A segunda é a obrigação de reparar o dano, quando 0 ato infracional acarretar prejuízos financeiros, podendo ser determinada a obrigação de restituir ou reparar o dano a vítima. A terceira trata-se da prestação de serviços à comunidade, que tem como objetivo proporcionar ao infrator a compreensão de valores sociais e a boa convivência comunitária, sendo desenvolvida por meio de parcerias públicas ou privadas, que deverão conduzir o adolescente em sua execução. A quarta refere-se a liberdade assistida, na qual o adolescente e sua família são acompanhados sistematicamente por uma equipe técnica. A quinta medida é a semiliberdade, aplicada ao adolescente sem privá-lo totalmente de sua liberdade, permitindo participar de atividades externas. A sexta e última a internação, trata-se de medida com privação de liberdade, a adolescentes que praticam ilícitos mais graves. (BRASIL, 1990).

Em janeiro de 2012 foi instituída a lei Federal no 12.594/2012, que cria o Sistema Nacional de Atendimento Socioeducativo - SINASE, para "regulamentar a execução das medidas socioeducativas destinadas a adolescentes que pratiquem ato infracional" (SINASE,2012, p.1), previstas no ECA. 
Quanto ao conceito SINASE e o entendimento de medidas socioeducativas, a Lei No. $12.594 \mathrm{diz}$ no $\S 10$ do Artigo 1०.:

[...] $\S 1^{\circ}$ Entende-se por Sinase o conjunto ordenado de princípios, regras e critérios que envolvem a execução de medidas socioeducativas, incluindo-se nele, por adesão, os sistemas estaduais, distrital e municipais, bem como todos os planos, políticas e programas específicos de atendimento a adolescente em conflito com a lei. $\S 2^{\circ}$ Entendem-se por medidas socioeducativas as previstas no art. 112 da Lei no 8.069 , de 13 de julho de 1990 (Estatuto da Criança e do Adolescente), as quais têm por objetivos: I a responsabilização do adolescente quanto às consequências lesivas do ato infracional, sempre que possível incentivando a sua reparação; II - a integração social do adolescente e a garantia de seus direitos individuais e sociais, por meio do cumprimento de seu plano individual de atendimento; e III - a desaprovação da conduta infracional, efetivando as disposições da sentença como parâmetro máximo de privação de liberdade ou restrição de direitos, observados os limites previstos em lei. (SINASE, 2012, Art.1\%).

Segundo Costa (2004) ao submeter o adolescente a um processo judicial, com todas garantias previstas em lei, e ser julgado culpado pela prática de ato infracional poderá ser aplicada a medida socioeducativa, sendo ela, uma "resposta formal da sociedade" (p.27) ao ato ilícito exercido pelo adolescente. Portanto sua responsabilização por não seguir as regras da lei penal será o motivo da imposição de medida socioeducativa.

A aplicação das medidas socioeducativas, deve sobretudo considerar e respeitar os direitos e garantias constitucionais previstos ao adolescente. O Artigo 228 da Carta Magna, que prevê prioritariamente a crianças e adolescentes a garantia de direitos, definindo o estado, a família e a sociedade como responsáveis por assegurálos. (BRASIL, 1988)

A dicotomia de educar e responsabilizar deve corroborar com a proposta socioeducativa das medidas, que tem como objetivos, entre outros, propor reflexões críticas, como também conscientizar os adolescentes quanto a responsabilização diante suas escolhas, atos e respectivas consequências, possibilitando que o jovem se observe como parte integrante da sociedade e passe a exercer em plenitude sua cidadania, como ser de direitos e deveres sociais, "do viver junto, do viver em sociedade" (DISTRITO FEDERAL, 2016a, P. 17). 


\subsection{CAMINHOS DO ADOLESCENTE INFRATOR NO SISTEMA SOCIOEDUCATIVO DO DISTRITO FEDERAL}

A Secretaria de Estado de Políticas para Crianças, Adolescentes e Juventude do Distrito Federal - SECRIANÇA, órgão do poder executivo, responsável, entre outras, pelas políticas públicas que visem a execução das medidas socioeducativas, previstas no Estatuto da Criança e do Adolescente.

Conforme descrito no primeiro Regimento Interno da SECRIANÇA, publicado em dezembro de 2016, com toda a estrutura da respectiva Secretaria, entre ela a Subsecretaria do Sistema Socioeducativo - SUBSIS, descrita no item 6 do referido regimento. Subordinadas a SUBSIS, temos, entre outras, a Coordenação de Internação e Semiliberdade, e a Coordenação das Unidades de Atendimento em Meio Aberto, responsáveis pela execução das medidas socioeducativas.

Quanto aos percursos do adolescente infrator, a partir do momento de sua apreensão em flagrante, ocorrida pela prática de ato infracional, o mesmo é encaminhado para a Delegacia da Criança e do Adolescente - DCA, em seguida para a Unidade de Atendimento Inicial - UAI.

O Relatório de Gestão da Subsecretaria do Sistema Socioeducativo - SUBSIS (2016c, p, 08) descreve a UAI, como

[...]unidade de entrada no sistema socioeducativo, e acautela adolescentes e
jovens que são apreendidos em flagrante ou em razão da existência de
Mandados de Busca e Apreensão em aberto. A UAl é parte integrante do
Núcleo de Atendimento Integrado - NAI, o qual, além da mencionada
unidade, conta com uma multiplicidade de órgãos e políticas de atendimento
aos adolescentes, dentre os quais se destacam o TJDFT, o MPDFT, a
Defensoria Pública, sistema de saúde e SEDESTMIDH. Destaca-se que o
adolescente recebe todo o atendimento social e jurídico, e passa pelo
processo de atendimento de forma muito mais célere, em regra deixando a
Unidade em um período aproximado de $24 h$, rumo a uma das unidades de
internação, semiliberdade, ou, no caso da aplicação de medidas de meio
aberto, bem como nos casos de liberação, sendo prontamente entregue à
família. (DISTRITO FEDERAL, 2016c, p. 08).

Após realizados os atendimentos previstos no Núcleo de Atendimento Integrado - NAI, o poder judiciário pode liberar o adolescente com ou sem aplicação de medidas em meio aberto, ou então encaminha-lo para a Unidade de Internação 
Provisória - medida cautelar. Vale destacar que durante a apuração de ato infracional pelo judiciário, o Artigo 183 do ECA prevê o prazo máximo para conclusão de quarenta e cinco dias, para que o adolescente permaneça internado provisoriamente, antes da sentença, de acordo com o previsto no Artigo 108 do ECA. (BRASIL, 1990)

Depois da apuração do ato infracional, respeitando os prazos previstos em lei, o jovem poderá ser liberado, com ou sem medida em meio aberto, ou encaminhado para alguma Unidade de Semiliberdade ou de Internação.

O Relatório de Gestão da SUBSIS (DISTRITO FEDERAL, 2016c) informa que no Distrito Federal existem quinze Unidades de Atendimento em Meio Aberto (UAMA), que executam as medidas socioeducativas de Liberdade Assistida - LA, e de Prestação de Serviços à Comunidade - PSC. Já as Unidades de Semiliberdade o Relatório de Gestão as descreve como cinco, sendo

Unidade de Semiliberdade Feminina do Guará - UFSG, Unidade de Semiliberdade de Santa Maria - USSM, Unidade de Semiliberdade do Recanto das Emas - USRE, Unidade de Semiliberdade do Gama - USG e Unidade de Semiliberdade de Taguatinga - UST. (GDF/SUBSIS, 2016c, p. $09)$.

No que concerne a medida socioeducativa de Internação, o mesmo relatório cita cinco Unidades de Internação estrita As Unidades de Internação Estrita (Unidade de Internação de Planaltina -
UIP, Unidade de Internação de São Sebastião - UISS, Unidade de Internação
do Recanto das Emas - UNIRE, Unidade de Internação de Santa Maria -
UISM e Unidade de Internação de Brazlândia - UIBRA) executam a medida
socioeducativa de Internação, na esteira do artigo 122 e seguintes do ECA.
(GDF/SUBSIS, 2016c, p. 08).

Vale destacar que o ECA em seu Artigo 121, § 3 (BRASIL, 1990, p. 104) afirma que "em nenhuma hipótese o período máximo de internação excederá a três anos". 


\subsection{LEVANTAMENTO DO QUANTITATIVO DE ESPECIALISTAS SOCIOEDUCATIVOS NAS UNIDADES}

Segue abaixo levantamento do quantitativo de servidores, Especialistas Socioeducativos - ESOCIO por unidade, descritos em três quadros, sendo (Unidades de Atendimento em Meio Aberto, Unidades de Semiliberdade e Unidades de Internação).

A coleta de dados foi realizada no Portal da Transparência do Distrito Federal (Servidores por órgão - Exercício 2017 / Órgão: Secretaria de Estado de Políticas Crianças, Adolescentes e Juventude / Situação: Ativo / Cargos / Lotações / Status: Normal), no site: http://www.transparencia.df.gov.br/\#/servidores/orgao, no dia 02/04/2017. Foi realizada a contagem de servidores Especialistas Socioeducativos ESOCIO e temporários, sendo os Pedagogos, os Psicólogos e os Assistentes Sociais, lotados nas Unidades de Atendimento em Meio Aberto - UAMA, nas Unidades de Semiliberdade, e nas Gerencias Sociopsicopedagógicas das Unidades de Internação.

Não foi possível realizar o levantamento do quantitativo de servidores por Unidade de Internação (estrita), visto que no Portal da Transparência do Distrito Federal não é descrita especificamente a Unidade de Internação na qual o servidor é lotado e sim a definição de locação como "gerencia sociopsicopedagógica", sendo possível realizar somente o levantamento geral de especialistas por cargo

$\mathrm{Na}$ Tabela 1, encontraremos a distribuição dos Especialistas Socioeducativos ESOCIO e temporários (Pedagogos, Psicólogos e Assistentes Sociais) lotados nas Unidades de Atendimento em Meio Aberto - UAMA, que executam medidas socioeducativas de Liberdade Assistida e Prestação de Serviços à Comunidade. 
TABELA 1 - Quantitativo de profissionais Especialistas Socioeducativos ESOCIO e temporários, lotados nas Unidades de Atendimento em Meio Aberto UAMA.

\begin{tabular}{|c|c|c|c|c|c|c|c|c|c|c|c|c|c|c|c|c|}
\hline \multirow{2}{*}{ SERVIDORES } & \multicolumn{15}{|c|}{ UNIDADES DE ATENDIMENTO EM MEIO ABERTO } & \multirow[b]{2}{*}{ 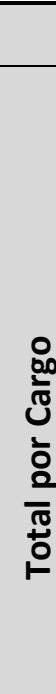 } \\
\hline & 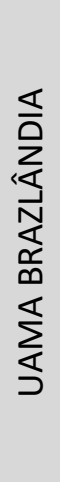 & 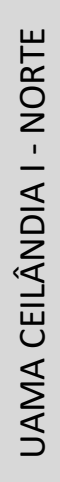 & 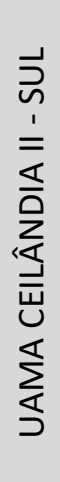 & 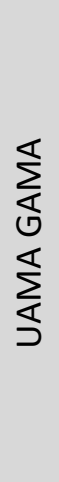 & 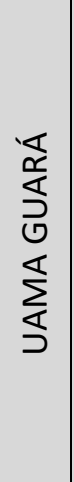 & 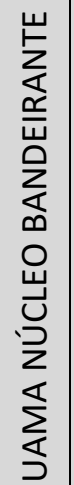 & 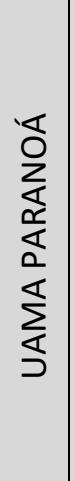 & 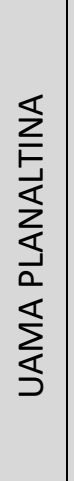 & 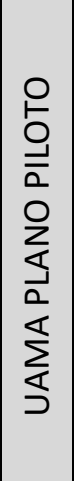 & 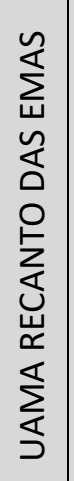 & 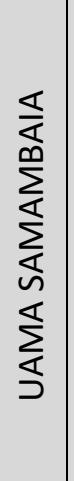 & 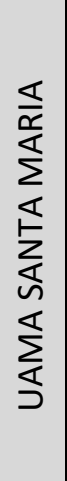 & 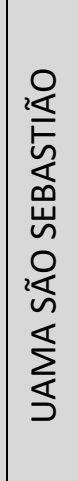 & 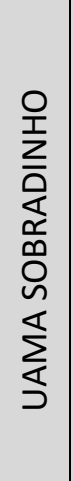 & 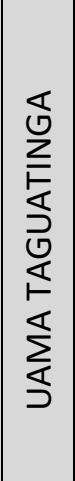 & \\
\hline $\begin{array}{c}\text { ESOCIO - ASSISTENTE } \\
\text { SOCIAL }\end{array}$ & 1 & 1 & 2 & 1 & 1 & 3 & 2 & 0 & 3 & 1 & 1 & 1 & 0 & 3 & 1 & 21 \\
\hline ESOCIO - PSICÓLOGO & 1 & 0 & 2 & 0 & 2 & 1 & 3 & 4 & 1 & 0 & 1 & 1 & 3 & 2 & 0 & 21 \\
\hline ESÓCIO - PEDAGOGO & 1 & 4 & 3 & 1 & 2 & 1 & 1 & 2 & 1 & 2 & 3 & 1 & 1 & 2 & 3 & 28 \\
\hline & & & & & TEMF & 'ORÁ & RIOS & & & & & & & & & \\
\hline SERVIÇO SOCIAL & 1 & 1 & 1 & 1 & 1 & 0 & 0 & 2 & 0 & 1 & 2 & 1 & 1 & 0 & 1 & 13 \\
\hline PSICÓLOGO & 0 & 1 & 2 & 2 & 0 & 0 & 0 & 0 & 0 & 1 & 2 & 1 & 0 & 0 & 1 & 10 \\
\hline PEDAGOGO & 0 & 0 & 0 & 0 & 0 & 0 & 0 & 0 & 0 & 0 & 0 & 1 & 1 & 0 & 0 & 2 \\
\hline \multicolumn{17}{|c|}{ RESUMO } \\
\hline $\begin{array}{c}\text { TOTAL - ASSISTENTE } \\
\text { SOCIAL }\end{array}$ & \multicolumn{16}{|c|}{34} \\
\hline TOTAL PSICÓLOGO & \multicolumn{16}{|c|}{31} \\
\hline TOTAL PEDAGOGO & \multicolumn{16}{|c|}{30} \\
\hline TOTAL GERAL & \multicolumn{16}{|c|}{95} \\
\hline
\end{tabular}

Fonte: Pesquisa realizada pelo autor no site: http://www.transparencia.df.gov.br/\#/servidores/orgao

Observa-se a Unidade de Atendimento em Meio Aberto de Ceilândia II - Sul como a unidade com maior quantitativo de profissionais - 10 (dez) e a de Brazlândia com o menor número - 04 (quatro).

$\mathrm{Na}$ Tabela 2, encontraremos a distribuição dos Especialistas Socioeducativos e temporários lotados nas Unidades de Semiliberdade. 
TABELA 2 - Quantitativo de profissionais Especialistas Socioeducativos ESOCIO e temporários, lotados nas Unidades de Semiliberdade.

\begin{tabular}{|c|c|c|c|c|c|c|}
\hline \multirow[b]{2}{*}{ SERVIDORES } & \multicolumn{6}{|c|}{ UNIDADES DE SEMILIBERDADE } \\
\hline & 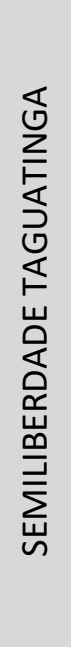 & 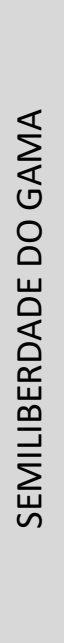 & 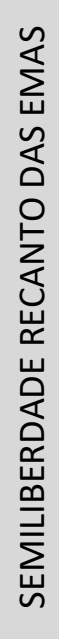 & 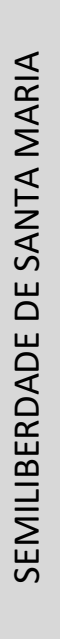 & 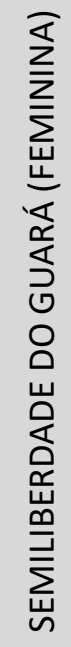 & 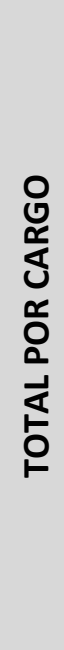 \\
\hline ESOCIO - ASSISTENTE SOCIAL & 3 & 1 & 1 & 0 & 1 & 6 \\
\hline ESOCIO - PSICÓLOGO & 2 & 0 & 1 & 1 & 1 & 5 \\
\hline ESÓCIO - PEDAGOGO & 3 & 0 & 1 & 1 & 2 & 7 \\
\hline \multicolumn{7}{|c|}{ TEMPORÁRIOS } \\
\hline SERVIÇO SOCIAL & 0 & 0 & 0 & 1 & 0 & 1 \\
\hline PSICÓLOGO & 0 & 0 & 0 & 0 & 0 & 0 \\
\hline PEDAGOGO & 0 & 0 & 0 & 0 & 0 & 0 \\
\hline \multicolumn{7}{|c|}{ RESUMO } \\
\hline TOTAL - ASSISTENTE SOCIAL & \multicolumn{6}{|c|}{7} \\
\hline TOTAL PSICÓLOGO & \multicolumn{6}{|c|}{5} \\
\hline TOTAL PEDAGOGO & \multicolumn{6}{|c|}{7} \\
\hline TOTAL GERAL & \multicolumn{6}{|c|}{19} \\
\hline
\end{tabular}

Fonte: Pesquisa realizada pelo autor no site: http://www.transparencia.df.gov.br/\#/servidores/orgao

Quanto as Unidades de Semiliberdade, nota-se que a de Taguatinga Norte é a que possui maior número de servidores, 08 (oito) especialistas. Observa-se que atualmente não existe nenhuma Unidade de Semiliberdade na região norte do Distrito Federal, o que pode dificultar o cumprimento da referida medida pelos adolescentes da citada região, como também o acompanhamento familiar, devido a distância e as dificuldades de transporte.

Na Tabela 3, trazemos a distribuição dos Especialistas Socioeducativos e temporários lotados nas Unidades de Internação. 
TABELA 3 - Quantitativo de profissionais Especialistas Socioeducativos ESOCIO e temporários, lotados nas Gerências Sociopsicopedagógicas, das Unidades de Internação.

\begin{tabular}{|c|c|c|c|c|c|}
\hline \multirow[b]{2}{*}{ SERVIDORES } & \multicolumn{5}{|c|}{ UNIDADES DE INTERNAÇÃO } \\
\hline & 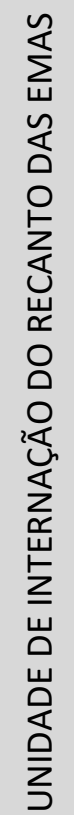 & 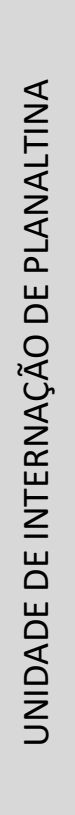 & 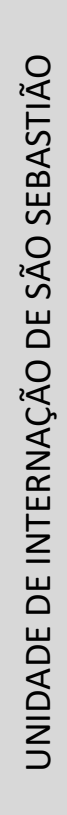 & 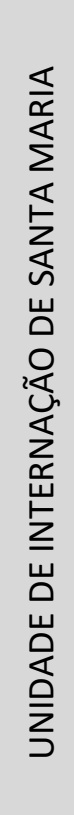 & 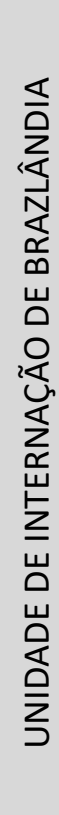 \\
\hline ESOCIO - ASSISTENTE SOCIAL & \multicolumn{5}{|c|}{25} \\
\hline ESOCIO - PSICÓLOGO & \multicolumn{5}{|c|}{26} \\
\hline ESÓCIO - PEDAGOGO & \multicolumn{5}{|c|}{24} \\
\hline \multicolumn{6}{|c|}{ TEMPORÁRIOS } \\
\hline SERVIÇO SOCIAL & \multicolumn{5}{|c|}{0} \\
\hline PSICÓLOGO & \multicolumn{5}{|c|}{0} \\
\hline PEDAGOGO & \multicolumn{5}{|c|}{0} \\
\hline \multicolumn{6}{|c|}{ RESUMO } \\
\hline TOTAL - ASSISTENTE SOCIAL & \multicolumn{5}{|c|}{25} \\
\hline TOTAL PSICÓLOGO & \multicolumn{5}{|c|}{26} \\
\hline TOTAL PEDAGOGO & \multicolumn{5}{|c|}{24} \\
\hline TOTAL GERAL & \multicolumn{5}{|c|}{75} \\
\hline
\end{tabular}

Fonte: Pesquisa realizada pelo autor no site: http://www.transparencia.df.gov.br/\#/servidores/orgao

Com estes dados organizados nas tabelas observa-se um universo de aproximadamente 189 profissionais Especialistas Socioeducativos e temporários (Pedagogos, Psicólogos e Assistentes Sociais) lotados nas UAMA, Unidades de Semiliberdade e Gerencias Sociopsicopedagógicas das Unidades de Internação estrita da SECRIANÇA. 


\title{
3.4 A SOCIOEDUCAÇÃO
}

O primeiro Plano Decenal de Atendimento Socioeducativo do Distrito Federal PDASE (2016a), previsto na lei SINASE, e com vigência (2015 - 2024) descreve a problemática socioeducativa como um problema educativo, sendo ela uma das áreas mais remotas e complexas da educação e de suas políticas.

De acordo com Bisinoto, Oliva, Arraes, Galli, Amorim, Souza (2016), a socioeducação

\begin{abstract}
configura-se como um conjunto articulado de programas, serviços e ações desenvolvidos a partir da inter-relação entre práticas educativas, demandas sociais e direitos humanos, com os objetivos de promover o desenvolvimento de potencialidades humanas, da autonomia e da emancipação, bem como fortalecer os princípios éticos da vida social. Partindo do entendimento de que as práticas educativas intencionais, planejadas e sistemáticas são propulsoras do desenvolvimento complexo dos adolescentes autores de atos infracionais, defende-se que a ação socioeducativa, orientada por uma clara concepção de socioeducação, tem o potencial de mobilizar novos posicionamentos juvenis para enfrentar a ordem e as regras sociais estabelecidas. (OLIVEIRA et al, 2016, p. 584).
\end{abstract}

Os autores, Oliveira et. al. (2016), entendem a socioeducação como ferramenta de emancipação do ser social e estimuladora de uma reflexão crítica emancipatória, como também de desenvolvimento do protagonismo e as mais diversas habilidades juvenis.

Antônio Carlos Costa afirma que:

O termo Protagonismo Juvenil, enquanto modalidade de ação educativa, é a criação de espaços e condições capazes de possibilitar aos jovens envolverem-se em atividades direcionadas a solução de problemas reais, atuando como fonte de iniciativa, liberdade e compromisso. (COSTA, 1999, p. 179).

No campo da educação, Costa (1999) define protagonismo juvenil como características de jovens que assumam o papel principal de sua vida, suas escolhas e caminhos e na solução de seus problemas. 


\subsection{O PEDAGOGO NA SOCIOEDUCAÇÃO}

De acordo com a Resolução do Conselho Nacional de Educação - Conselho Pleno - CNE/CP número 01, de 15 de maio de 2006, que define as Diretrizes para o curso de licenciatura em Pedagogia, em seu artigo. $5^{\circ}$. descreve algumas das habilidades de um graduado em Pedagogia.

IV - trabalhar em espaços escolares e não-escolares, na promoção da aprendizagem de sujeitos em diferentes fases do desenvolvimento humano, em diversos níveis e modalidades do processo educativo; (Resolução CNE, 2006, p.2) Grifo nosso.

Ou seja, os espaços de atuação do pedagogo vão além dos ambientes escolares. Alcançam os mais diversos espaços onde se estabelecem processos educativos.

Segundo Libâneo (2001, apud AMORIM, 2014) o pedagogo é o especialista que pode atuar nas mais diversas modalidades da ação educativa, associadas ao processo de ensino aprendizagem, tendo como meta a formação do ser humano, estabelecido em seu contexto histórico.

Diante dessa realidade que contextualiza a prática pedagógica nos diversos espaços educativos, trataremos neste trabalho a atuação do pedagogo na socioeducação, especificamente em sua atuação nos grupos socioeducativos, junto a adolescentes que convivem em conflito com as regras e normas sociais, que se atribua a autoria de ato infracional, descritos pelo pedagogo Antônio Carlos Gomes da Costa (2001) como "adolescentes em dificuldade".

Segundo o professor Antônio Carlos Gomes da Costa em sua obra intitulada "Pedagogia da Presença":

Espera-se do jovem em dificuldade que ele se integre no corpo social como elemento produtivo e ordeiro, sem suscitar qualquer forma de reprovação do meio. A essa altura, então diz-se que o educando foi "socializado". $\mathrm{Na}$ perspectiva de uma pedagogia crítica, esta não é a verdadeira socialização, que situa muito além desta adesão rudimentar à ordem estabelecida. Segundo o enfoque da Pedagogia da Presença, está socializado o jovem que dá importância a cada membro da sociedade e a todos os homens, respeitando-os na sua pessoa, nos seus direitos, nos seus bens. Ele agirá assim não apenas por uma lei promulgada ou por meio de sanções, mas por uma ética pessoal que determina o outro como valor em relação a si próprio. (COSTA, 2001, p.46). 
Para Costa (2001) a verdadeira socialização não está associada simplesmente ao fato de seguir e respeitar as regras sociais. A socialização vai muito além dessa concepção. Consiste em educar o adolescente e torná-lo um ser crítico, e assim possibilitar ao jovem, assimilar e refletir acerca dos valores do ser humano, e que o mesmo tenha a capacidade de respeitar a si mesmo e ao próximo de modo integral e contínuo independente das imposições e das regras sociais.

No que tange as competências do pedagogo, dia 14 de fevereiro de 2017 foi publicada a Portaria № 35, de 13 de fevereiro de 2017, que aprovou o Manual Sociopsicopedagógico das Unidades de Internação do Sistema Socioeducativo do Distrito Federal, unidades públicas que executam medidas socioeducativas de Internação, vinculadas a Secretaria de Estado de Políticas para Crianças. Adolescentes e Juventude do DF - SECRIANÇA. Esse manual descreve as atribuições comum aos Especialistas Socioeducativos (Pedagogos, Assistentes Sociais e Psicólogos) lotados nas Gerências Sociopsicopedagógicas - GESPP das Unidades de Internação, entre elas:

Promover atividades estratégicas que estimulem a educação para a paz, os valores éticos para uma boa convivência grupal e institucional, projetando-se para uma convivência comunitária saudável; (DISTRITO FEDERAL, 2017, p.31).

Quanto as atribuições específicas do Especialista Socioeducativo - Pedagogo, de acordo com o manual (DISTRITO FEDERAL, 2017) estão previstas, entre outras, o acompanhamento dos socioeducandos em atividades cotidianas, em oficinas ocupacionais que resultem em processos de aprendizagem, orientar os adolescentes na elaboração de projeto de vida, na busca de novos caminhos e possibilidades, elaborar e executar projetos específicos da sua área de atuação.

Sobre as atribuições comuns aos especialistas socioeducativos (Pedagogos, Assistentes Sociais e Psicólogos) o manual cita a necessidade do acompanhamento sistemático com atendimentos "individuais e/ou em grupo, buscando desenvolver uma escuta ativa; e intervisões por meio de uma presença educativa" (DISTRITO FEDERAL, 2017, p. 30).

Para o pedagogo Antônio Carlos 
Conferir cidadania pedagógica ao trabalho social e educativo dirigido ao adolescente infrator e a outros grupos em situação de risco é, pois, uma tarefa urgente e necessária. Precisamos começar a fazer pedagogia para que não continue a predominar, nessa área de atividade, a transgressão sistemática dos direitos humanos e de cidadania dessa fração relegada da nossa infância e da nossa juventude. (COSTA, 1999, p. 27).

Diante dessa realidade vale destacar a importância da pedagogia no processo socioeducativo e na sua contribuição para a formação cidadã dos adolescentes.

\subsection{GRUPO SOCIOEDUCATIVO}

Considerando as perspectivas da socioeducação como possibilidades de transformação para e por meio do convívio social, Libâneo (1998) apresenta as concepções interacionistas da educação que descrevem a interação social, as trocas de experiências interpessoais como oportunidades de aprendizado e de construção de conhecimentos.

Segundo Bareicha (2010) o grupo socioeducativo tem por objetivo proporcionar um ambiente de acolhida das problemáticas comuns do grupo, partilhar expectativas e possibilitar decisões coletivas. Para Zanella e Pereira (2001, p. 109) "O grupo começa a anunciar-se de fato quando aparecem mobilizações coletivas, ou então, quando participantes assumem lugares que visavam a representação de todos."

Contudo Costa (1999, p. 134) descreve que "uma das características mais comuns de adolescentes em dificuldade vem do fato de não se sentirem aceitos pelas pessoas." Segundo o autor é necessário estabelecer um vínculo com o adolescente, e com isso favorecer a autoestima e a autoconfiança, fundamentais para a criação de um projeto de vida.

Costa (1999) entende que

a educação é uma oficina onde educador e educando trabalham uma relação capaz de resultar em instrumentos que possibilitem ao educando, nos planos pessoal e social, exercitar sua iniciativa, sua liberdade e sua capacidade de comprometer-se consigo mesmo e com os outros. (COSTA, 1999, p. 43).

A libertação autêntica consiste, para o educador Paulo Freire (2013), na percepção e atuação dos homens acerca do mundo para assim modificá-lo. 
O que nos parece indiscutível é que, se pretendemos a libertação dos homens não podemos começar por aliená-los ou mantê-los alienados. A libertação autêntica, que é a humanização em processo, não é uma coisa que se deposita nos homens. Não é uma palavra a mais, oca, mitificante. É práxis, que implica a ação e a reflexão dos homens sobre o mundo para transformálo. (FREIRE, 2013, p. 93).

Para Freire (2013, p.96) "ninguém educa ninguém, como também ninguém educa a si mesmo: os homens se educam em comunhão, mediados pelo mundo". Diante dessa afirmação podemos refletir sobre os possíveis alcances do grupo socioeducativo, a comunhão de saberes, as trocas de experiências, as descobertas sociais, sendo acontecimentos que visem contribuir para a constante construção e reconstrução coletiva da proposta educativa, e a formação social do ser, e assim cooperar com a socioeducação.

Do ponto de vista da "Pedagogia da Presença" Costa (1999) afirma que a relação de integração entre educandos e educadores é baseada na reciprocidade, revelando suas presenças, com novos conteúdos, novas formas, desde que não sejam questionadas suas individualidades.

\begin{abstract}
A reciprocidade é quase sempre o fator que explica aqueles sucessos que surgem inesperadamente, quando todas as esperanças razoáveis já foram por terra. Por trás desses resultados aparece sempre uma pessoa-chave, que consegue manter com o jovem em dificuldade uma relação pessoal que se mostrou capaz de restituir-lhe um valor no qual ele próprio já não acreditava. Alguém compreendeu e acolheu suas vivências, sentimentos e aspirações, a partir de sua própria experiência e comunicou-lhe com clareza a solidariedade e a força para agir. (COSTA, 1999, p. 75).
\end{abstract}

Essa reciprocidade é fundamental para enxergar o outro de forma individual, mesmo nos grupos socioeducativos, pois cada socioeducando possui valores e percepções de mundo, porém em sua grande maioria, adolescentes carentes de oportunidades e perspectivas. Daí, como diz Costa (1999) a necessidade de atuar solidariamente despertando habilidades e aspirações, e assim proporcionar aos educandos uma relação que alcance resultados qualitativos e que contribua sistematicamente com os objetivos socioeducativos.

Concebemos o homem como ser capaz de assumir-se como sujeito de sua história e da História, agente de transformação de si e do mundo, fonte de iniciativa, liberdade e compromisso nos planos pessoal e social. (COSTA, 1999, p. 27). 


\subsection{O PROTAGONISMO JUVENIL}

Como parte do processo socioeducativo Costa (1999) entende ser de grande relevância propiciar cotidianamente junto aos adolescentes, reflexões críticas e ações que desenvolvam a prática do planejamento e a realização de projetos diversos com objetivo de proporcionar aos socioeducandos a autoconfiança e sua autoestima.

É o planejamento e execução, como foi planejado, de projetos pontuais -
produzir e vender um trabalho, realizar um mutirão com este ou aquele fim,
conceber, organizar e dirigir uma festa, ensaiar e apresentar com sucesso um
número de música, dança, poesia ou teatro. Em sua simplicidade, esses
pequenos projetos, ao se realizarem, dão ao educando a experiência da
vitória e, por meio dela, a confiança em si mesmo, a autoestima e o
autoconceito tão necessários a quem se proponha a reorientar o curso de sua
própria existência. (COSTA, 1999, p. 47).

As escolhas e a participação ativa do socioeducando no processo socioeducativo são fundamentais, como por exemplo, a importância que deve ser dispensada na opinião do adolescente em políticas socioeducativas que lhe dizem respeito e o afetam diretamente. O jovem deve sentir-se respeitado e valorizado nesse processo, sendo ferramentas importantíssimas para exercitar e estimular o protagonismo juvenil no âmbito social e pessoal.

Antônio Carlos Costa (1999), em sua obra intitulada "Aventura Pedagógica" afirma que "educar é sempre uma aposta no outro" (p. 14). Para o autor é fundamental focar nas qualidades do socioeducando, não no que ele não sabe, mais sim no que sabe, com o que pode contribuir, no que cada um tem de bom, em suas experiências e habilidades.

Como se vê, quando nos referimos à angustia e ao risco da aventura pedagógica, estamos falando de alguma coisa bem concreta. A aposta no outro exige do educador não apenas competência técnica, mas também solidariedade humana e compromisso político com o educando. (COSTA, 1999, p. 20).

O socioeducador precisa acreditar no sujeito alvo de sua intervenção pedagógica, nesse caso o adolescente autor de ato infracional, e no potencial transformador do socioeducando para assim assumir integralmente seu papel no processo socioeducativo. (COSTA, 1999). 
Já o socioeducando deve descobrir suas potencialidades e aprender consigo mesmo e com o outro, e por meio da educação alcançar a real libertação. (FREIRE, 2013).

Para o educador Paulo Freire a necessidade da ação libertadora

Se faz indispensável aos oprimidos, para a luta por sua libertação, que a realidade concreta de opressão já não seja para eles uma espécie de "mundo fechado"(em que gera o seu medo da liberdade) do qual não pudessem sair, mas uma situação que apenas os limita e que eles podem transformar, é fundamental, então, que, ao reconhecerem o limite que a realidade opressora Ihes impõe, tenham, neste reconhecimento, o motor de sua ação libertadora. (FREIRE, 2013, p. 48).

Jacques Delors (2003) entende que não basta o acúmulo de conhecimentos desde o início da vida, sem que estejamos aptos para tirar proveito e explorá-lo durante toda a vida.

Para poder dar resposta ao conjunto de suas missões, a educação deve organizar-se em torno de quatro aprendizagens fundamentais que, ao longo de toda a vida serão de algum modo para cada indivíduo, os pilares do conhecimento: aprender a conhecer, isto é adquirir os instrumentos da compreensão; aprender a fazer, para poder agir sobre o meio envolvente; aprender a viver juntos, a fim de participar e cooperar com os outros em todas as atividades humanas; finalmente aprender a ser, via essencial que integra as três precedentes. (DELORS, 2013, p. 89-90).

Diante dessas ideias e concepções do processo educativo, observa-se a pedagogia de grupos, as atividades coletivas, como terrenos férteis para o processo socioeducativo, visto contribuir para o desenvolvimento de novos saberes por meio, da interação, da troca de experiências, das opiniões, mediadas pelos socioeducadores e pela concepção que cada um tem de mundo e assim estimular o autoconhecimento, a autonomia, a iniciativa, aspectos que favorecem o protagonismo, fazendo que o adolescente se observe como o personagem principal de sua vida e de suas escolhas, mediado pelas regras de boa convivência social e assim fortalecendo os vínculos familiares e sociais. 


\section{METODOLOGIA}

O primeiro capítulo foi constituído de pesquisa bibliográfica com o objetivo de introduzir a temática abordada a partir de conceitos e ideias de autores diversos. Gil (1991) descreve a esse tipo de pesquisa como a realizada por meio de obras já desenvolvidas, normalmente livros e artigos de cunho científico.

Contudo a metodologia utilizada considerando os aspectos da pesquisa, e a necessidade de realizar entrevistas semiestruturada com servidores que atuam junto ao público de adolescentes em cumprimento de medidas socioeducativas, priorizouse o foco na pesquisa qualitativa, que segundo Creswell (2010) apresenta tratamento distinto, quando comparados as metodologias quantitativas. Neste foco metodológico Creswell (2010) enfatiza que

A investigação qualitativa emprega diferentes concepções filosóficas; estratégias e investigação; e métodos de coletas, análise e interpretação dos dados. Embora os processos sejam similares, os procedimentos qualitativos baseiam-se em dados de texto e imagem, tem passos singulares na análise dos dados e se valem de diferentes estratégias de investigação. (CRESWELL, 2010, p. 206).

As entrevistas semidiretivas "(também chamadas com plano, com guia, com esquema, focalizadas, semiestruturadas), mais curtas e mais fáceis: seja qual for o caso, devem ser registradas e integralmente transcritas" Bardin (2016, p. 93). Cabe destacar que o objetivo da pesquisa está focado nas atividades realizadas em grupo e que se deve levar em consideração os saberes, as percepções, as ideias e as vivências de cada participante das entrevistas.

\subsection{OBJETIVOS DA PESQUISA}

O objetivo da pesquisa é investigar os alcances e os limites das atividades em grupo, como práticas educativas, realizadas por profissionais - especialistas socioeducativos (Pedagogos, Assistentes Sociais e Psicólogos) - que atuam nas unidades que executam medidas socioeducativas no DF, sejam medidas em meio aberto, semiliberdade ou em estabelecimento educativo de internação. 


\subsection{DOS PARTICIPANTES DA ENTREVISTA}

Quanto aos participantes das entrevistas, tratam-se de Especialistas Socioeducativos (Pedagogos, Psicólogos e Assistentes Sociais), da Carreira Socioeducativa, vinculados a Secretaria de Estado de Políticas para Crianças, Adolescentes e Juventude do Distrito Federal.

Foram entrevistados 30 (trinta) servidores, que correspondem a um percentual de aproximadamente $15,87 \%$ da totalidade dos profissionais Especialistas Socioeducativos - ESOCIO (Psicólogos, Pedagogos e Assistentes Sociais) lotados nas unidades que executam as medidas socioeducativas e que trabalham diretamente no atendimento a adolescentes em cumprimento de medidas socioeducativas e suas famílias, tendo como foco a coleta de dados para realizar pesquisa qualitativa acerca da temática da Pedagogia de Grupos.

\subsection{PROCEDIMENTO DE COLETA E REGISTRO DE DADOS}

Diante a metodologia adotada para o desenvolvimento da pesquisa, observase relevante a coleta de dados por meio de entrevistas semiestruturadas, com a elaboração de um Roteiro de Entrevista, ver Apêndice A, aplicado junto aos Especialistas Socioeducativos. As entrevistas foram gravadas mediante autorização prévia dos entrevistados e assinatura de Termo de Consentimento Livre e Esclarecido - TCLE. Cabe destacar que foi preservada a identidade dos participantes na pesquisa.

Para Babbie (1999, p. 259) "Há várias vantagens em ter um questionário aplicado por entrevistadores, em lugar de respondido pelos próprios respondentes". Uma delas, segundo Babbie (1999) são maiores percentuais de respostas, outra vantagem, de acordo com o autor, é a possibilidade de observar atentamente o entrevistado.

Quanto a coleta de dados Creswell diz que

O pesquisador como instrumento fundamental - Os pesquisadores qualitativos coletam pessoalmente os dados por meio de exame de documentos, de observação do comportamento ou de entrevista com os participantes. Eles podem utilizar um protocolo - instrumento para a coleta de dados, mas são eles próprios que coletam as informações. (CRESWELL, 2010, p.208). 
A coleta de dados ocorreu no decorrer de duas semanas do mês de maio de 2017, mediante agendamento prévio junto as unidades, em sua maioria no período matutino, das $8 \mathrm{~h}$ (horas) até as $11 \mathrm{~h} 30$ (onze horas de trinta minutos), sendo esse período o tempo disponível pelo pesquisador para a coleta dos dados. Vale destacar que os profissionais executam suas atividades em horário corrido, ou seja, normalmente metade da equipe está pela manhã e a outra metade no período vespertino.

\subsection{ANÁLISE DOS DADOS}

Neste enfoque metodológico Creswell (2010) entende que o objetivo da pesquisa qualitativa é investigar os diversos elementos que abrangem o tema central e demonstrar o ponto de vista e as concepções dos participantes.

Para o tratamento dos dados colhidos por meio das entrevistas será adotado a análise de conteúdo, que segundo Bardin (2016, p. 37), "é um conjunto de técnicas de análise das comunicações". Para Oliveira et al (2003) a análise de conteúdo são métodos de investigação de documentos que visam observar as principais ideias e temas descritos em texto específico.

De acordo com Oliveira et al.

$\mathrm{Na}$ área de educação, a análise de conteúdo pode ser, sem dúvida, um instrumento de grande utilidade em estudos, em que os dados coletados sejam resultados de entrevistas (diretivas ou não), questionários abertos, discursos ou documentos oficiais, textos literários, artigos de jornais, emissões de rádio e de televisão. Ela ajuda o educador a retirar do texto escrito seu conteúdo manifesto ou latente. (OLIVEIRA et al, 2003, p. 5).

Para Bardin (2016) o trato das informações possibilita o pesquisador inferir os saberes, pontos de vista, conhecimentos do emissor, como também do meio ao qual está inserido.

Foi realizada a transcrição dos dados coletados por meio da entrevista para posterior organização da análise do conteúdo, adotando como referencial 
metodológico a teoria de Bardin (2016). Inicialmente observou-se a necessidade de realizar análise categorial para melhor organização dos dados apresentados, sendo os mesmos categorizados por tipo de medida socioeducativa, tais como: Internação, Semiliberdade e Unidade de Atendimento em Meio Aberto - UAMA.

Durante a análise dos conteúdos coletados, os entrevistados serão descritos como $E$, ou seja, o entrevistado 1 será $E 1$, entrevistado 2 será $E 2$, e assim sucessivamente.

\subsection{CRONOGRAMA}

Para a elaboração do projeto de pesquisa, o levantamento bibliográfico, a solicitação de autorizações dos órgãos competentes, coleta de dados por meio de entrevistas semiestruturadas, e a análise do conteúdo, foi planejado o seguinte cronograma:

TABELA 4 - Cronograma de Atividades

\begin{tabular}{|c|l|l|l|l|}
\hline ATIVIDADES & MAR & ABR & MAI & JUN \\
\hline Elaboração do pré projeto de pesquisa & & & & \\
\hline Encontros com o orientador & & & & \\
\hline Solicitar autorização para pesquisa (VEMSE e SECRIANÇA) & & & & \\
\hline Pesquisa bibliográfica & & & & \\
\hline $\begin{array}{r}\text { Realizar entrevista semiestruturada junto aos servidores } \\
\text { (Especialistas Socioeducativos) }\end{array}$ & & & & \\
\hline Análise dos dados coletados & & & & \\
\hline Revisão do texto & & & & \\
\hline Conclusão e entrega do Trabalho Final & & & \\
\hline
\end{tabular}

Fonte: O autor 


\section{RESULTADO E ANÁLISE DOS DADOS}

Como dito anteriormente foram realizadas entrevistas semiestruturadas, com 30 Especialistas Socioeducativos (Pedagogos, Psicólogos e Assistentes Sociais) lotados especificamente nas Unidades de Atendimento em Meio Aberto - UAMA, que executam medidas socioeducativas em meio aberto (Liberdade Assistida - L.A, e Prestação de Serviços à Comunidade - PSC), nas Unidades de Semiliberdade e nas Unidades de Internação, vinculadas à Secretaria de Estado de Políticas para Crianças, Adolescentes e Juventude do Distrito Federal, mediante autorização prévia da Vara de Execução de Medidas Socioeducativas - VEMSE e da respectiva Secretaria de Estado.

Para as entrevistas foi elaborado um Roteiro de Entrevista, ver Apêndice A, para orientação e apoio do entrevistador durante a coleta dos dados. O roteiro foi dividido em quatro partes. A primeira parte refere-se à caracterização do respondente. A segunda trata-se das perguntas relacionadas ao atendimento em grupos. A terceira parte pergunta sobre os critérios de avaliação dos atendimentos em grupo. A quarta parte corresponde as perguntas relacionadas a conceituação.

\subsection{CARACTERIZAÇÃO DOS ENTREVISTADOS}

Segue abaixo características dos entrevistados durante a coleta de dados:

- Gênero dos entrevistados: 26 - Feminino / 04 - Masculino;

- A média de idade dos entrevistados: 37 anos;

- A média do tempo de experiência com grupos socioeducativos: 7 anos.

Quanto aos participantes observa-se maioria do gênero feminino. Das 26 (vinte e seis) entrevistadas: 14 (quatorze) são lotadas nas Unidades de Atendimento em Meio Aberto - UAMA; 08 (oito) são lotadas nas Unidades de Internação; e 04 (quatro) nas Unidades de Semiliberdade.

Os participantes do gênero masculino, total de 04 (quatro), sendo: 03 (três) das Unidades de Atendimento em Meio Aberto, e 01 (um) de Unidade de Semiliberdade. 
TABELA 5 - Quantitativo de profissionais entrevistados por cargos e unidades do sistema socioeducativo do Distrito Federal.

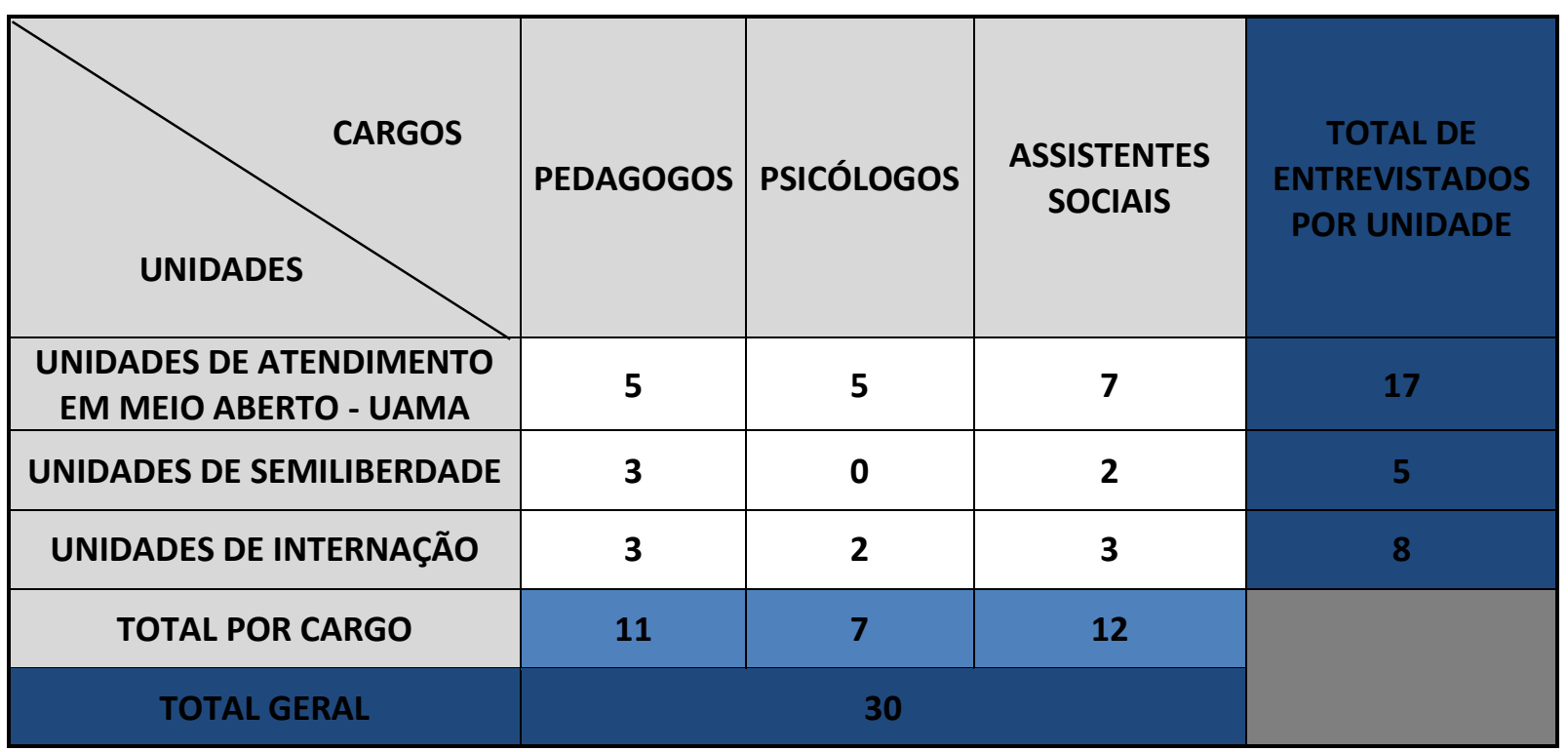

Fonte: O autor.

Participaram da entrevista 17 (dezessete) profissionais lotados nas Unidades de Atendimento em Meio Aberto - UAMA, 05 (cinco) profissionais lotados nas Unidades de Semiliberdade e 08 (oito) profissionais lotados nas Unidades de Internação.

No total foram entrevistados 11 (onze) Pedagogos, 07 (sete) psicólogos e 12 (doze) Assistentes Sociais.

\subsection{GRUPOS SOCIOEDUCATIVOS - INTERNAÇÃO}

Segue abaixo quadro confeccionado a partir da análise dos dados coletados por meio da entrevista semiestruturada, com a utilização do roteiro de entrevista, junto a 08 (oito) Especialistas Socioeducativos lotados especificamente em Unidade de Internação. 
QUADRO 1 - Respostas por categorias e na ordem decrescente de repetições dos entrevistados que atuam em medida socioeducativa de Internação.

\begin{tabular}{|c|c|c|c|c|c|c|}
\hline \multicolumn{7}{|c|}{ INTERNAÇÃO } \\
\hline $\begin{array}{l}\text { OBJETIVOS } \\
\text { PEDAGÓGICOS }\end{array}$ & SOCIOMETRIA & DIDÁTICA & $\begin{array}{l}\text { CONTEÚDO } \\
\text { PROGRAMÁTICO }\end{array}$ & $\begin{array}{c}\text { BENEFíCIOS DO } \\
\text { TRABALHO EM GRUPO }\end{array}$ & $\begin{array}{c}\text { PRINCIPAIS } \\
\text { DIFICULDADES PARA } \\
\text { REALIZAR GRUPOS }\end{array}$ & $\begin{array}{c}\text { COMO SÃO AVALIADOS / } \\
\text { CRITÉRIOS }\end{array}$ \\
\hline $\begin{array}{c}\text { Diminuir } \\
\text { conflitos/rixas/guerras/ } \\
\text { violência (4) } \\
\text { Diminuir uso de } \\
\text { drogas } \\
\text { Estimular o } \\
\text { Protagonismo Juvenil } \\
\text { Falta de percepção da } \\
\text { família }\end{array}$ & $\begin{array}{c}\text { Demandas que emergem do } \\
\text { grupo (8) } \\
\text { Após entrevistas e triagem (7) } \\
\text { Grupos por ala/quarto/módulo } \\
\text { (6) } \\
\text { Grupos Pequenos - } \\
\text { duplas/trios/cinco (2) } \\
\text { Por faixa etária (2) } \\
\text { Pela escolarização (2) } \\
\text { Questões de segurança } \\
\text { Pela maturidade do jovem }\end{array}$ & $\begin{array}{c}\text { Dinâmicas em grupo (6) } \\
\text { Músicas/coral (5) } \\
\text { Textos (2) } \\
\text { Atividades lúdicas } \\
\begin{array}{c}\text { Torneio/gincana Cultura da } \\
\text { paz }\end{array}\end{array}$ & $\begin{array}{c}\text { Mercado de } \\
\text { trabalho/profissionalização/ } \\
\text { currículo/escolarização (13) } \\
\text { Cultura da paz/ } \\
\text { violências/violência contra } \\
\text { mulher (8) } \\
\text { Temas emergentes: } \\
\text { autoestima/ respeito/ } \\
\text { liberdade/paternidade } \\
\text { responsável (4) } \\
\text { Convivência em grupo (3) } \\
\text { Protagonismo Juvenil (3) } \\
\text { Atos/contextos infracionais } \\
(2) \\
\text { Drogas, DST (2) } \\
\text { Cidadania (2) } \\
\text { Sustentabilidade (2) } \\
\text { Direitos e deveres } \\
\text { Fortalecimento dos vínculos } \\
\text { familiares } \\
\text { Empreendedorismo } \\
\text { Esportes } \\
\text { Relacionados com PIA* e } \\
\text { Relatórios }\end{array}$ & $\begin{array}{c}\text { Convivência interpessoal } \\
(5) \\
\text { Adquirir novos } \\
\text { conhecimentos / saberes } \\
\text { Novas oportunidades (2) } \\
\text { Troca de ideias (2) } \\
\text { Mudanças de } \\
\text { comportamento (2) } \\
\text { Estimular a proatividade (2) } \\
\text { Disciplina } \\
\text { Estimular o protagonismo } \\
\text { juvenil } \\
\text { Desenvolver Habilidades } \\
\text { Maior reflexão dos } \\
\text { adolescentes } \\
\text { Melhoraram a higiene } \\
\text { Mudança de visão durante } \\
\text { os atendimentos } \\
\text { Parar de se autolesionar } \\
\text { Resgatar sentimentos } \\
\text { Reduzir a introspecção } \\
\text { Resultados positivos } \\
\text { Se perceber } \\
\text { Troca de experiências }\end{array}$ & $\begin{array}{l}\text { Pouca mobilidade (4) } \\
\text { Questões de segurança (4) } \\
\text { Falta de servidores (3) } \\
\text { Logística da unidade (3) } \\
\text { Falta de espaços específicos } \\
\text { adequados (2) } \\
\text { Descontinuidade do trabalho } \\
(2) \\
\begin{array}{c}\text { Proteção da integridade física } \\
(2) \\
\text { Juntar adolescentes novatos } \\
\text { com veteranos/com } \\
\text { diferentes níveis de } \\
\text { escolarização. } \\
\text { Mudanças de gestão }\end{array}\end{array}$ & 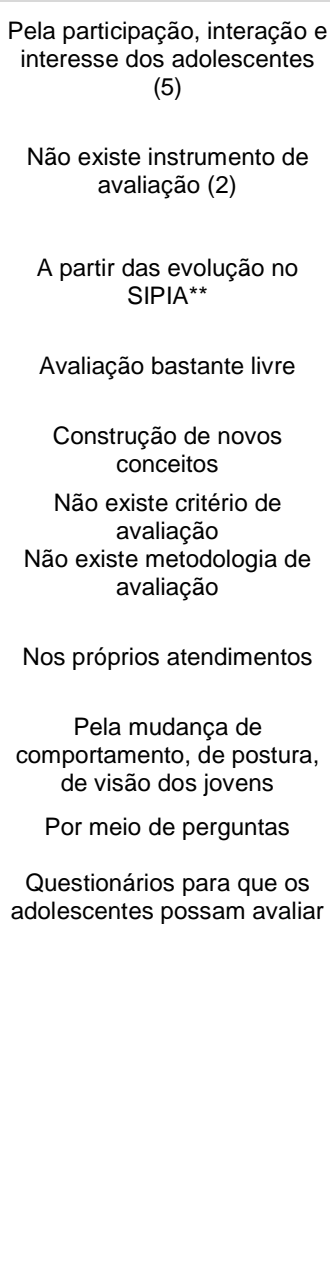 \\
\hline
\end{tabular}

**SIPIA - Sistema de Informações para Infância e Adolescência. Site:<http://www.sipia.gov.br/>

Fonte: $\mathrm{O}$ autor. 
Começamos a análise com as respostas dos entrevistados que atuam especificamente em medida socioeducativa de internação.

Ao realizar a pergunta 2.1: "Como são organizados os grupos para atendimento socioeducativo?" (forma, motivos, número de pessoas, espaço físico dos atendimentos) observou-se maior repetição de alguns dados.

Quanto aos objetivos pedagógicos para a realização dos grupos socioeducativos, destaca-se como mecanismo para reduzir a questão dos conflitos, das rixas, das guerras entre os adolescentes, de trabalhar a questão da drogadição, de estimular o protagonismo juvenil, trabalhar temas relacionados a necessidades dos socioeducandos.

Normalmente é realizada triagem individual por meio de entrevistas, pesquisas junto aos adolescentes, sendo os mesmos organizados por quarto, ala ou módulo. No grupo deve-se observar questões de segurança, sendo que normalmente são realizados grupos pequenos.

As principais temáticas abordadas durante a realização dos grupos estão associadas ao mundo do trabalho, a profissionalização, com dicas e auxílio na confecção do currículo e a escolarização. Temas voltados para a cultura da paz, com o objetivo propor reflexões e estimular a convivência pacífica em grupo. Questões relacionadas a violências, como por exemplo a violência contra a mulher, a drogas, a doenças sexualmente transmissíveis - DST, ao empreendedorismo, a cidadania e a temas que estimulem o Protagonismo Juvenil e o fortalecimento dos vínculos familiares e sociais.

E6: "O outro tema também que tem sido trabalhado com os adolescentes é a cultura da paz, para tentar mediar conflitos e fazer com que os adolescentes possam verificar que existem outras maneiras de resolver os conflitos. Que na vivência deles os conflitos são resolvidos com violência. Então nessa cultura da paz foi colocado isso, outras formas de resolver conflitos que não seja a violência."

Também se trabalham temas emergentes, normalmente relacionados a liberdade, a autoestima, o respeito e a responsabilização, temas de grande relevância para trabalhar em grupo. 
Os espaços físicos para realização dos grupos socioeducativos costumam ser em salas específicas, auditórios ou até mesmo no próprio módulo de convivência. $A$ média de participantes varia bastante. Se for no auditório pode chegar a uma média de 15 (quinze) participantes, se em salas de atendimento aproximadamente 04 (quatro) participantes.

A pergunta 2.2: "Os temas abordados são escolhidos previamente ou emergem do grupo?"

As respostas relatam que geralmente os temas são previamente organizados de acordo com o perfil e a necessidade dos socioeducandos, entretanto costumam emergir temáticas e demandas dos grupos. Uma entrevistada relata que

\begin{abstract}
E5 - [...] "no atendimento, nós trabalhamos desde questões que os próprios adolescentes trazem, de dificuldades vivenciadas no próprio módulo, vivenciadas na escola, em alguma atividade, bem como outras temáticas que o profissional, a partir da leitura que ele faz do perfil daqueles socioeducandos, são escolhidas pelo próprio profissional. Nós temos autonomia técnica para construir e definir essas temáticas. Eu particularmente trabalho muito com o protagonismo juvenil" [...].
\end{abstract}

Ou seja, mesmo escolhendo previamente os temas a serem trabalhados no grupo, outras temáticas que podem emergir durante a realização do grupo.

No tocante aos critérios de avaliação dos grupos socioeducativos, alguns entrevistados relataram que os participantes do grupo são frequentemente avaliados pela participação, pelo interesse nas atividades realizadas, pela interação com os demais integrantes do grupo e pela mudança de comportamento.

Houve relatos de não existir instrumental, critérios, nenhuma metodologia específica para a avaliação do grupo e que normalmente acontece de a avaliação ser bastante livre, o que pressupõe não haver padronização, nem uniformização das formas e dos critérios de avaliação.

Os principais recursos didáticos utilizados na realização dos grupos são audiovisuais como filmes e vídeos. Também palestras com convidados, rodas de conversa, realização de oficinas temáticas e dinâmicas de grupo, com músicas, atividades lúdicas e coral. 
Foram descritos alguns benefícios do trabalho em grupo, como possibilitar a convivência interpessoal, a interação entre os participantes, a oportunidade de adquirir novos conhecimentos, novos saberes, de desenvolver habilidades, de estimular o protagonismo juvenil, a criatividade, oportunizar a troca de ideias e experiências.

Relataram também algumas dificuldades para realizar atividades coletivas na medida socioeducativa de internação, sendo atualmente a pouca mobilidade dos jovens uma das principais dificuldades para realizar o trabalho em grupo, devido a escassez de recursos humanos e questões específicas da logística e da segurança da unidade.

Descrevem também a falta de espaços adequados para os atendimentos coletivos e o fato de não haver um trabalho contínuo na realização dos grupos socioeducativos.

No próximo subcapítulo vamos analisar os dados colhidos durante entrevistas realizadas com os especialistas socioeducativos lotados em unidades que executam medidas socioeducativas de Semiliberdade.

\subsection{GRUPOS SOCIOEDUCATIVOS - SEMILIBERDADE}

Segue abaixo quadro confeccionado a partir da análise dos dados coletados por meio da entrevista semiestruturada, com a utilização do roteiro de entrevista, junto aos 05 (cinco) Especialistas Socioeducativos lotados especificamente em Unidade de Semiliberdade: 
QUADRO 2 - Respostas por categorias e na ordem decrescente de repetições dos entrevistados que atuam em medida socioeducativa de Semiliberdade.

\begin{tabular}{|c|c|c|c|c|c|c|}
\hline \multicolumn{7}{|c|}{ SEMILIBERDADE } \\
\hline $\begin{array}{l}\text { OBJETIVOS } \\
\text { PEDAGÓGICOS }\end{array}$ & SOCIOMETRIA & DIDÁTICA & $\begin{array}{c}\text { CONTEÚDOS } \\
\text { PROGRAMÁTICOS }\end{array}$ & $\begin{array}{l}\text { BENEFícIOS DO } \\
\text { TRABALHO EM } \\
\text { GRUPO }\end{array}$ & $\begin{array}{c}\text { PRINCIPAIS } \\
\text { DIFICULDADES PARA } \\
\text { REALIZAR GRUPOS }\end{array}$ & $\begin{array}{c}\text { COMO SÃO } \\
\text { AVALIADOS/CRITÉRI } \\
\text { OS }\end{array}$ \\
\hline $\begin{array}{l}\text { Acolher e sensibilizar o } \\
\text { jovem sobre os } \\
\text { aspectos de seu } \\
\text { cotidiano e qual o seu } \\
\text { papel nele. }\end{array}$ & $\begin{array}{c}\text { Temas que } \\
\text { emergem do grupo } \\
\text { (8) } \\
\text { Temas } \\
\text { previamente } \\
\text { elaborados (4) } \\
\text { Prontuário (3) } \\
\text { Intervenções } \\
\text { coletivas (2) } \\
\text { Saber se o } \\
\text { participante está a } \\
\text { vontade } \\
\text { Grupos abertos } \\
\text { Grupos de famílias } \\
\text { Grupos } \\
\text { socioeducativos } \\
\text { Livro de registros }\end{array}$ & $\begin{array}{l}\text { Palestras/parcerias (9) } \\
\text { Dinâmicas de grupo (7) } \\
\text { Filmes (6) } \\
\text { Oficinas temáticas (3) } \\
\text { Colagens } \\
\text { Debates } \\
\text { Desenhos } \\
\text { Grafites } \\
\text { Músicas } \\
\text { Rodas de conversa }\end{array}$ & $\begin{array}{c}\begin{array}{c}\text { Drogas, DST, prevenção } \\
(11)\end{array} \\
\begin{array}{c}\text { Profissionalização/ } \\
\text { mercado de } \\
\text { trabalho/escolarização } \\
(8)\end{array} \\
\begin{array}{c}\text { Violências/violência } \\
\text { doméstica (5) } \\
\text { Cidadania }\end{array} \\
\text { Esporte, cultura e lazer } \\
\text { Mundo das artes } \\
\text { Política } \\
\text { Relações afetivas } \\
\text { Sexualidade }\end{array}$ & 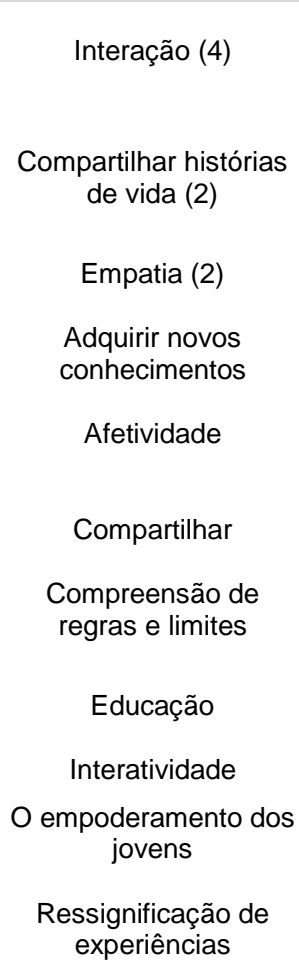 & $\begin{array}{c}\text { Ausência de espaço } \\
\text { apropriados (3) } \\
\text { Reunir os jovens dado que } \\
\text { estão em atividades } \\
\text { externas durante o dia (2) } \\
\text { Evasão }\end{array}$ & 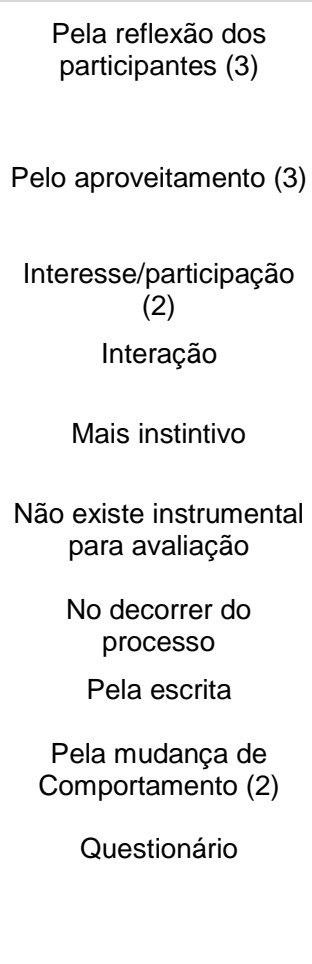 \\
\hline
\end{tabular}

Fonte: $\mathrm{O}$ autor. 
Nesse capítulo abordaremos a análise dos dados coletados junto aos profissionais que executam medida socioeducativa de Semiliberdade.

Quanto aos objetivos pedagógicos para a realização dos grupos, os entrevistados descrevem a necessidade de acolher e sensibilizar o jovem sobre aspectos de seu cotidiano e qual o seu papel nele.

As temáticas normalmente emergem do grupo, o que não exclui a possibilidade de existirem temas previamente elaborados. Também são realizados grupos com as famílias dos adolescentes, conforme descreve entrevistado.

E21 - "Na nossa organização de trabalho, a gente sempre procura assegurar
encontros, no mínimo mensais, preferencialmente quinzenais, no tocante a
realização de trabalhos com grupos, entre os jovens e também promovemos
esse tipo de trabalho com as famílias. Em ambos os casos a gente observa
que realmente é um momento da realização do trabalho extremamente rico
para o sucesso da proposta da socioeducação. Tanto com foco e o olhar para
o grupo dos socioeducandos, como o das suas famílias."

O número de participações nos grupos de famílias - GF gira em torno de 15 participantes. Já o número de participações de jovens é em média 06 (seis) socioeducandos. Porém devemos considerar que a proposta da medida socioeducativa de semiliberdade permite que os jovens possam estudar, fazer cursos profissionalizantes, trabalhar, e muitas vezes passam o dia fora da unidade.

E21 - "Com relação a jovens, como na unidade de semiliberdade, como o nome sugere, eles podem fazer uso de todos os serviços comunitários, e é extremamente positivo que saiam realmente para estudar, para fazer cursos profissionalizantes, para trabalhar."

Os principais recursos didáticos utilizados são as dinâmicas de grupo, filmes, parcerias, palestras, rodas de conversa e oficinas temáticas com o intuito de trabalhar conteúdos relacionados a drogas, a doenças sexualmente transmissíveis e formas de prevenção, a profissionalização, ao mundo do trabalho e a escolarização, a violências, a esporte, a cultura, e ao lazer. Também surgem temas sobre, política, cidadania, sexualidade e relações afetivas.

Os entrevistados citaram que os principais benefícios do trabalho em grupo é a possibilidade de interação, o compartilhamento de histórias de vida, de colocar em 
prática a empatia, em criar e compreender regras e limites, a aquisição de novos conhecimentos e o empoderamento dos adolescentes.

As principais dificuldades encontradas para a realização dos grupos na unidade de semiliberdade é a ausência de espaços apropriados e a evasão dos jovens. Os espaços físicos utilizados para a realização dos grupos é um ateliê (espaço multiuso), espaços externos e na própria unidade.

Uma das entrevistadas relata que

E27 - "Hoje a gente utiliza somente uma sala não muito grande. A unidade não tem auditório, não tem um espaço reservado para acomodação de mais adolescentes, então a gente realiza em uma sala mesmo, como se fosse uma sala de aula. Um espaço mais ou menos assim. Só tem essa sala."

$\mathrm{Na}$ medida de semiliberdade normalmente os grupos socioeducativos são avaliados por meio da reflexão dos participantes, do interesse, do aproveitamento e participação acerca dos assuntos abordados, da interação com outros participantes e pela mudança de comportamentos.

\subsection{GRUPOS SOCIOEDUCATIVOS - LIBERDADE ASSISTIDA E PRESTAÇÃO DE SERVIÇOS À COMUNIDADE}

Segue abaixo quadro confeccionado a partir da análise dos dados coletados por meio de entrevista semiestruturada, com a utilização do roteiro de entrevista, junto a 17(dezessete) Especialistas Socioeducativos lotados especificamente em Unidades de Atendimento em Meio Aberto - UAMA, que executam medidas socioeducativas de Liberdade Assistida e de Prestação de Serviços à Comunidade. 
QUADRO 3 - Respostas por categorias na ordem decrescente de repetições dos entrevistados que atuam em medida socioeducativa de Liberdade Assistida e Prestação de Serviços à Comunidade.

\begin{tabular}{|c|c|c|c|c|c|c|}
\hline \multicolumn{7}{|c|}{ UNIDADES DE ATENDIMENTO EM MEIO ABERTO } \\
\hline OBJETIVOS PEDAGÓGICOS & SOCIOMETRIA & DIDÁTICA & CONTEÚDO PROGRAMÁTICO & $\begin{array}{l}\text { BENEFÍCIOS DO TRABALHO EM } \\
\text { GRUPO }\end{array}$ & $\begin{array}{l}\text { PRINCIPAIS DIFICULDADES } \\
\text { PARA REALIZAR GRUPOS }\end{array}$ & $\begin{array}{c}\text { COMO SÃO AVALIADOS/ } \\
\text { CRITÉRIOS }\end{array}$ \\
\hline $\begin{array}{l}\text { Promover escuta aos } \\
\text { adolescentes e ampliação } \\
\text { de sua visão de mundo, } \\
\text { fortalecendo vínculos } \\
\text { sociais e com a escola; } \\
\text { oportunizando } \\
\text { profissionalização e } \\
\text { atividades de cultura e } \\
\text { lazer. }\end{array}$ & $\begin{array}{l}\text { Grupos de famílias GF (12) } \\
\text { Grupo de meninas (5) } \\
\text { Grupos de adolescentes (4) } \\
\text { Convite (3) } \\
\text { Entrevistas (3) } \\
\text { Dividido em eixos do SINASE } \\
\text { Grupos de adolescentes e } \\
\text { comunidade (2) } \\
\text { Por faixa etária (2) } \\
\text { Convocação por telegrama } \\
\text { Grupos de acolhimento } \\
\text { Grupos de adolescentes e } \\
\text { familias } \\
\text { Grupo de masculinidades } \\
\text { Pactuar regras } \\
\text { Pelo perfil dos adolescentes } \\
\text { Planejamentos } \\
\text { Pontualidade } \\
\text { Por temática } \\
\text { Profissionais de referência } \\
\text { Projetos } \\
\text { Registros dos grupos }\end{array}$ & $\begin{array}{c}\text { Rodas de conversa (10) } \\
\text { Oficinas (dança/teatro) (11) } \\
\text { Palestras (8) } \\
\text { Parceiros (7) } \\
\text { Passeios (7) } \\
\text { Convidado (6) } \\
\text { Futebol (6) } \\
\text { Grupos temáticos (5) } \\
\text { Colagem (4) } \\
\text { Debates (4) } \\
\text { Músicas (4) } \\
\text { Desenhos/pintura/mandalas (3) } \\
\text { Cartazes (2) } \\
\text { Contação de histórias (2) } \\
\text { Documentários (2) } \\
\text { Reflexões (2) } \\
\text { Saídas externas (2) } \\
\text { Escrita } \\
\text { Meditação }\end{array}$ & $\begin{array}{l}\text { Mercado de } \\
\text { trabalho/profissionalização/ } \\
\text { escolarização (19) } \\
\text { Esporte, cultura e lazer (8) } \\
\text { Histórias de vida (7) } \\
\text { Violência (6) } \\
\text { Adolescências (2) } \\
\text { Habilidades e competências (2) } \\
\text { Questões específicas de Gênero (2) } \\
\text { Orientação sexual/sexualidade (2) } \\
\text { Uso de drogas (2) } \\
\text { Cidadania } \\
\text { Competências } \\
\text { Comportamento } \\
\text { Contexto infracional } \\
\text { Conceito de família } \\
\text { Empreendedorismo } \\
\text { Estresse } \\
\text { Identidade } \\
\text { Protagonismo Juvenil } \\
\text { Saúde } \\
\text { Limites na relação de pais e filhos } \\
\text { Mulheres que fizeram história }\end{array}$ & $\begin{array}{c}\text { Integração social (10) } \\
\text { Compartilhar } \\
\text { vivências/experiências (5) } \\
\text { Acesso/estímulo a espaços } \\
\text { culturais (3) } \\
\text { Compartilhar conhecimentos (2) } \\
\text { Adquirir novos conhecimentos } \\
\text { Identificar lideranças } \\
\text { O empoderamento do adolescente } \\
\text { O jovem sente mais segurança }\end{array}$ & $\begin{array}{c}\text { Baixa adesão (5) } \\
\text { Espaço físico inadequado } \\
\text { (3) } \\
\text { Conflitos entre os jovens } \\
\text { (2) } \\
\text { Falta de recursos humanos } \\
\text { (2) } \\
\text { Transporte (2) } \\
\text { Falta de comunicação dos } \\
\text { profissionais } \\
\text { Falta de interesse dos } \\
\text { jovens } \\
\text { Falta de interesse dos } \\
\text { profissionais } \\
\text { Falta de recursos para } \\
\text { lanches }\end{array}$ & $\begin{array}{c}\text { Avaliado no coletivo pela } \\
\text { equipe (6) } \\
\text { Não é sistematizado (5) } \\
\text { Pela } \\
\text { participação/motivação / } \\
\text { interesse (9) } \\
\text { Pela frequência (4) } \\
\text { Temos que evoluir muito } \\
\text { (4) } \\
\text { Feedback dos } \\
\text { participantes (3) } \\
\text { Não tem instrumental } \\
\text { (3) } \\
\text { Não tem metodologia (3) } \\
\text { Pela percepção dos } \\
\text { servidores (3) } \\
\text { Instrumental de } \\
\text { avaliação (2) } \\
\text { Não é padronizada (2) } \\
\text { Avaliação empírica } \\
\text { Avaliação dos } \\
\text { participantes } \\
\text { Avaliação dos servidores } \\
\text { Pela mudança de } \\
\text { comportamento } \\
\text { Pelos relatórios } \\
\text { Pela quantidade de } \\
\text { participantes }\end{array}$ \\
\hline
\end{tabular}


A seguir iremos descrever a análise dos dados coletados junto aos participantes da entrevista lotados nas Unidades de Atendimento em Meio Aberto.

No que tange as medidas socioeducativas em meio aberto, podemos destacar como principal objetivo pedagógico para a realização de grupos socioeducativos a necessidade de promover escuta aos adolescentes e ampliação de sua visão de mundo, fortalecendo vínculos sociais e com a escola, oportunizando profissionalização e atividades de esporte cultura e lazer.

Normalmente os temas são escolhidos previamente, porém muitas temáticas emergem do grupo. São realizados grupos de adolescentes, grupos com adolescentes abertos para a comunidade, grupos de adolescentes e familiares, grupos de famílias, grupos específicos de meninas.

Os principais recursos didáticos utilizados são os audiovisuais, como um projeto de cinema que acontece nas unidades, com programação semanal de filmes para os adolescentes e aberto a comunidade local. Após assistir o filme é realizado um debate. Nos grupos também são utilizadas dinâmicas de grupos, rodas de conversa, palestras, oficinas temáticas, passeios e atividades de esporte, cultura e lazer.

Os conteúdos abordados nos grupos são voltados a profissionalização, ao mundo do trabalho, a escolarização, ao esporte, a cultura, ao lazer. São espaços apropriados para compartilhar histórias de vida, falar sobre adolescências, cidadania, desenvolver habilidades e competências. Debates sobre violências, orientação sexual e sexualidade, saúde, uso de drogas, limites na relação de pais e filhos e protagonismo juvenil.

Os entrevistados destacam como benefícios do grupo a integração social, a possibilidade de compartilhar vivências, experiências e conhecimentos. Estimular o acesso a espaços culturais, o empoderamento do adolescente. Fortalecer vínculos e também identificar lideranças.

Os espaços físicos utilizados para a realização dos grupos são em salas de atendimento nas próprias unidades, em espaços da comunidade, em espaços cedidos por outros órgãos públicos e ao ar livre. 
As dificuldades encontradas na realização dos grupos com adolescentes em cumprimento de medidas em meio aberto são a baixa adesão dos jovens, questões relacionadas a conflitos, rixas entre os socioeducandos, problemas relativos a transporte, já que muitos jovens residem longe da unidade no qual estão vinculados.

Outro problema é a falta de recursos humanos e de espaços físicos adequados para o trabalho com grupos o que costuma prejudicar a realização das atividades.

A média de participações varia de acordo com a atividade proposta. Normalmente existe a necessidade de chamar um número bem maior de adolescentes devido à baixa adesão aos grupos. Porém há grupos com uma maior adesão como por exemplo do grupo de futebol.

Quanto a avaliação dos grupos, normalmente são avaliados em coletivo pela equipe técnica, por meio da participação, frequência, pelo feedback dos participantes, pelo interesse e pelo comportamento. Também houve relatos que a avaliação não é padronizada, sistematizada e que não existe instrumental avaliativo.

E17 - [...]"o ideal seria a Secretaria proporcionar, e não só a Secretaria, mas todo mundo que está envolvido nela, e trabalha, servidores ou não, em fazer algo padrão juntos. Porque senão cada um avalia de uma forma, aí você não tem um dado estatístico bom. Não só estatístico, mas qualitativo também."

Alguns descrevem possuir instrumental de avaliação e outros entendem a necessidade de evoluir nos aspectos de avaliação dos grupos.

\subsection{DA CONCEITUAÇÃO}

\subsubsection{DOS REFERENCIAS TEÓRICO-METODOLÓGICOS}

A análise da conceituação foi separada pelas categorias de profissionais, sendo uma categoria Pedagogos e outra demais especialistas. 


\subsubsection{PARTICIPANTES PEDAGOGOS}

Alguns mencionaram Paulo Freire como autor de referência, outros citam como referencial teórico-metodológico a Pedagogia da Presença, do autor Antônio Carlos Gomes da Costa. Também tiveram relatos de autores como Donald Winnicott da teoria antissocial e de referenciais teóricos da Pedagogia Social.

Apesar das referências citadas por alguns pedagogos ao trabalhar grupos socioeducativos tiveram também os pedagogos que relataram não adotar referencias teóricos nem autores específicos para o trabalho prático com os grupos socioeducativos.

Acredita-se que a prática pedagógica com grupos socioeducativos deve ser constantemente aperfeiçoada e transformada, tendo como objetivos a educação, a transformação social do ser, aliada a prática cientifica, as experiências, e referenciais teórico-metodológicos.

\subsubsection{PARTICIPANTES DEMAIS ESPECIALISTAS}

Quanto aos demais especialistas (psicólogos e assistentes sociais), alguns também disseram não seguir autores nem teorias específicas. Outros citam autores como Paulo Freire, Antônio Carlos Gomes da Costa, Paula Gomide e Mario Volpi.

Houve os que descreveram alguns referenciais teóricos com a teoria behaviorista, a Pedagogia da Presença, a teoria rogeriana centrada na pessoa, teorias do Psicodrama, como o role playing, Gestalt e a teoria Socio-histórica.

Nota-se presente a utilização de teorias de autores como Paulo Freire e Antônio Carlos Gomes da Costa, tanto por alguns profissionais da pedagogia quanto de outras especificidades que trabalham com grupos socioeducativos. 


\subsubsection{COMO OS PARTICIPANTES DEFINEM GRUPO SOCIOEDUCATIVO}

Após a análise dos relatos dos participantes acerca da definição de Grupo Socioeducativo foi possível inferir que existem diversos conceitos e pontos de vista sobre a temática.

Alguns participantes demonstraram insegurança ao definir o conceito, iniciando a fala com palavras e frases como: "não sei se vou definir..."; "Complexa..."; "Difícil conceituar..."; "É bem complexo"; "Pergunta difícil de responder"; "É uma questão crítica"; "Me pegou de surpresa".

Podemos observar desde então que os conceitos na maioria das vezes não convergiram. Analisar as opiniões, os pontos de vista, as ideias acerca da definição de grupo socioeducativo possibilitaram uma análise mais crítica, um olhar mais sensível, visto a riqueza dos dados coletados.

Tiveram conceitos dos mais diversos. Vejamos alguns exemplos:

E4 - "Então... a meu ver é a presença de servidores de várias áreas, seja da segurança, especialistas, escola, atuando num grupo de adolescentes diversos... eu acredito que seja isso, porque na verdade, mesmo as áreas sendo diferentes, o objetivo aqui é um só, que é a socioeducação."

E11 - "Mas eu entendo que o grupo socioeducativo é muito essa perspectiva de ter um foco dos adolescentes em cumprimento de medida socioeducativa, e aí eu consigo definir grupo só mesmo pelo o que faz o grupo. Eu não consigo definir muito pelo conceito, mas pelo que faz parte desse grupo. Mas que seriam os adolescentes atendidos, as famílias acompanhadas e a equipe técnica que maneja esses grupos. Mas eu não consigo trazer para você claramente o que seria um grupo socioeducativo".

E19 - "Acho que é uma forma da gente trabalhar a interação desses jovens, com outros jovens, mesmo com a família, a formação de vínculos. Isso é muito importante para gente. A gente vê o resultado com esse socioeducando e também com essa família, que é chamada também a participar desse processo."

E20 - "Um grupo é uma reunião de pelos menos três pessoas, em uma atividade, portanto coletiva, que tem data, local e finalidade. No caso do grupo socioeducativo, a finalidade não é outra senão aquela de a atividade servir para orientar o nosso socioeducando. Então ela tem um caráter educativo. Um caráter muitas vezes modelar, onde nós também seguimos as regras que são pactuadas, nós prestamos a orientação, nós cobramos os limites das regras do grupo. Mas então é um espaço propício, para coletivamente vivenciarmos um tempo, espaço, numa atividade pedagógica, com a finalidade de fazer a socioeducação acontecer."

E25 - "Bom, acho que é isso... Interação entre os meninos e que provoca algum tipo de reflexão e que leve eles para frente, para um lugar que eles escolherem, que a gente pensa que seria um projeto positivo para eles." 
E26 - "O grupo socioeducativo se formaria com as pessoas que estão diretamente ligadas no atendimento do jovem, seja ele ATRS, seja ele professor, seja ele especialista, que juntos, isso estou te falando no plano ideal, não é o plano real não, não é isso que acontece. Juntos teriam metas e objetivos a serem traçados e para serem alcançados com esse jovem. Isso para mim seria um grupo socioeducativo. Que poderia ter uma perspectiva e um resultado. Você ter bem definido quais são os objetivos, quais são as metas e como é essa metodologia que a gente vai utilizar enquanto grupo socioeducativo, enquanto pessoas que estão lidando com esse jovem."

E30 - [...] "trata-se de uma reunião não intencional ou de escolha individual de adolescentes cujas semelhanças estão no fato de estarem na mesma fase de desenvolvimento psicossocial, no fato de terem sido autores de atos infracionais e, muitas vezes, serem oriundos de realidades parecidas".

Houve uma participante que fez duas análises acerca do conceito de grupo socioeducativo:

\begin{abstract}
E28 - "Se eu for pegar a palavra sociedade e educação. Eu diria que todos nós somos e fazemos parte do grupo socioeducativo. Todos nós! Porque nós somos sociedade e nós temos, de acordo com a legislação, sociedade, família e estado, todos tem a obrigação de participar. Esse é o grupo socioeducativo. Primeira análise.

Segunda análise: $O$ grupo socioeducativo foi puxado para a questão infracional. Quem é o grupo socioeducativo nessa segunda análise? Os jovens que cometeram algum ato infracional e seus familiares e os servidores executores das medidas socioeducativas, que é a internação, semiliberdade, liberdade assistida e prestação de serviços à comunidade".
\end{abstract}

Na primeira análise a entrevistada E28 descreve o termo socioeducação como a junção das palavras "sociedade" e "educação" e entende que toda a sociedade compõe o grupo socioeducativo. Já na segunda análise relata que o grupo socioeducativo foi puxado para a questão infracional e descreve o grupo como os jovens infratores, seus familiares e servidores que acompanham a execução das medidas socioeducativas.

$\mathrm{Na}$ Figura 1 estão descritas as características relatadas pelos entrevistados durante as entrevistas semiestruturadas nas unidades que executam medidas socioeducativas. 


\section{FIGURA 1 - Características do Grupo Socioeducativo - GS segundo os entrevistados:}

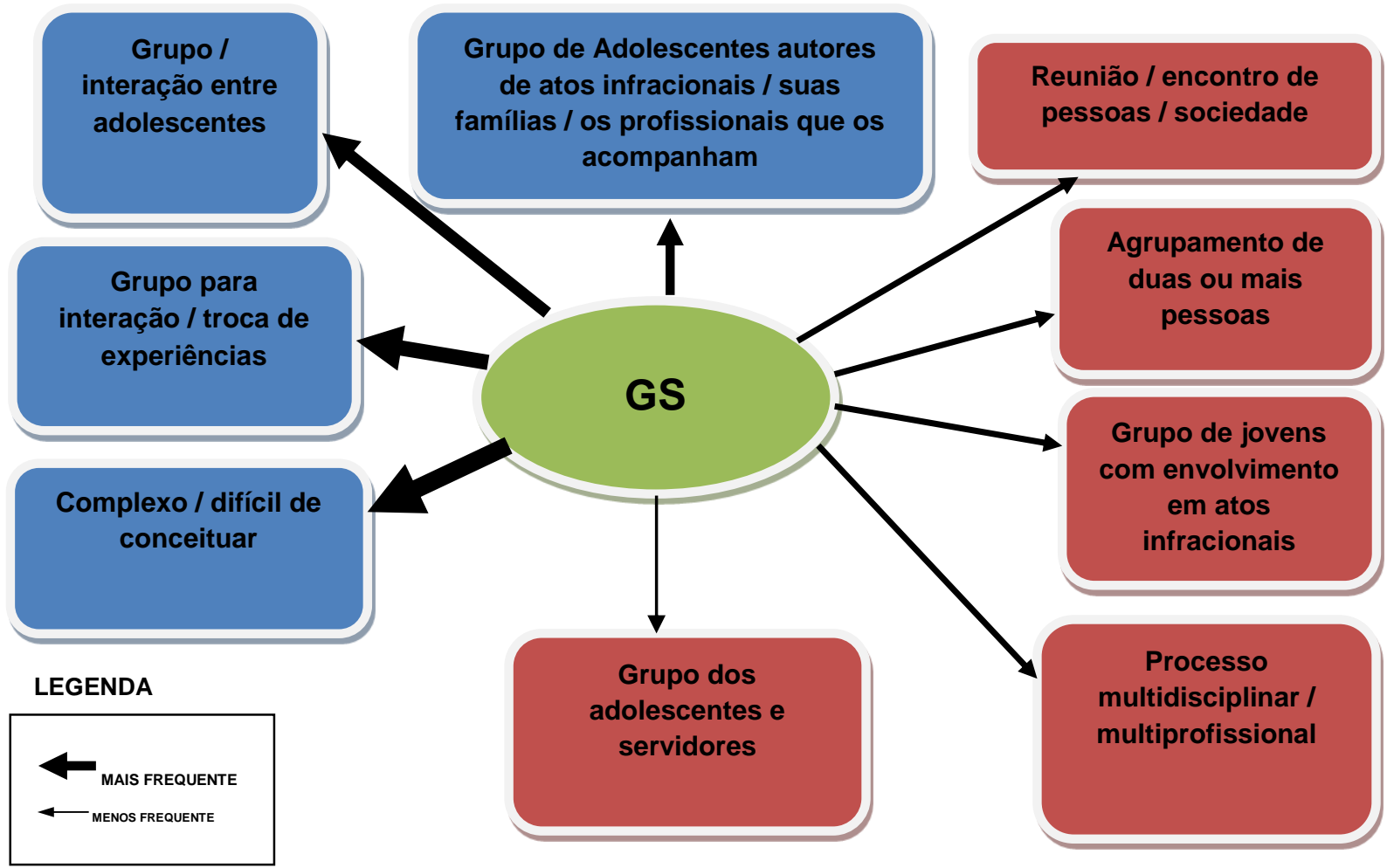

Fonte: o autor.

Apesar da divergência de entendimentos, nota-se que para vários participantes da pesquisa o grupo socioeducativo está diretamente associado a adolescentes infratores que estão em cumprimento de alguma medida socioeducativa.

Observamos que a lei 12.594/12 que instituiu o Sistema Nacional de Atendimento Socioeducativo (SINASE) se apropriou do termo "socioeducativo", o que muitas vezes pode dar a entender que o termo socioeducação limita-se apenas a adolescentes que pratiquem atos infracionais, e que estão em cumprimento de alguma medida socioeducativa, suas famílias e os profissionais envolvidos. O termo socioeducação é muito mais amplo e abrange bem mais do que adolescentes, ou adolescentes infratores ou medidas socioeducativas. 


\subsubsection{SUGESTÕES PARA A UNIVERSIDADE}

O objetivo da última pergunta da entrevista foi colher sugestões dos participantes para a universidade melhorar a formação dos profissionais para atendimento de grupos socioeducativos.

Foi realizada a pergunta: "Qual a sua sugestão para a Universidade melhorar a formação para atendimento de grupo socioeducativo?

Houve relatos como por exemplo:

E26 - "[...] eu me encontrei na medida socioeducativa. Gosto muito, sou apaixonada pelo meu trabalho... Mas na faculdade não me foi apresentado... Acho que poderia ser incluído na grade... de alguma forma apresentado para os acadêmicos essa oportunidade também de ocupar esse campo de trabalho, porque a gente chega aqui sem saber nada. Eu cheguei aqui sem saber nada... Toda a minha formação foi para sala de aula... E isso dificulta."

Os entrevistados puderam contribuir com diversas sugestões, como por exemplo: Mais investimentos em ensino, pesquisa e extensão voltados para a temática socioeducativa. A universidade mais próxima da comunidade, dos espaços interventivos. Mais atividades práticas, estágios, parcerias, oferta de grade de disciplinas para os mais diversos cursos e que lidam com a socioeducação, com mais debates e investimento em metodologias de grupo.

Outros relatos dos participantes:

E5 - [...] "eu acho que os alunos chegam com uma abordagem, um conteúdo teórico metodológico bastante vasto, interessante. São profissões interventivas, mas que não tem, muitas vezes, essa preparação para a intervenção. Então o aluno, muitas vezes chega totalmente despreparado para essa intervenção. Essa intervenção em grupo, essa formação para o atendimento em grupo, eu penso que ela tinha que ser melhor explorada [...]".

E21 - "Acho que tem várias possibilidades. Por exemplo: oferecer disciplinas, oferecer atividades de extensão. Acho que extensão é uma excelente oportunidade, porque você vai aplicar algo relacionado a academia, mas no espaço comunitário, na sociedade, então é uma situação bem real. Mais até que uma disciplina. A disciplina vai te trazer as questões teóricas.... Poderia ser as duas coisas, disciplinas em diferentes espaços, na pedagogia, na psicologia, no serviço social[...]".

E23 - "Penso que quanto mais aproximado for a relação da universidade com as instituições, no meu ponto de vista, mais qualidade se terá esse trabalho, tendo em vista que a universidade se constitui no seu tripé: de ensino, pesquisa e extensão. E por esses propósitos, imagina-se que todos que estão envolvidos nesse cenário estão dedicando mesmo do seu tempo, de suas 
energias, para estar acessando todos os saberes e conhecimentos relacionados à determinadas práticas, e o fornecimento e a construção conjunta desses avanços no universo dos saberes, dos conhecimentos, com os profissionais dos diferentes campos".

E31 - "Participar de forma mais ativa e fisicamente presente da realidade da Unidade, compartilhar conhecimento através de seminários, fóruns[...]".

Segue abaixo figura ilustrativa com as sugestões dos participantes para a universidade melhorar a formação para o trabalho com Grupos Socioeducativos - GS.

FIGURA 2 - Sugestões para conteúdos e práticas na Universidade em socioeducação a serem trabalhados nos eixos educação, pesquisa e extensão:

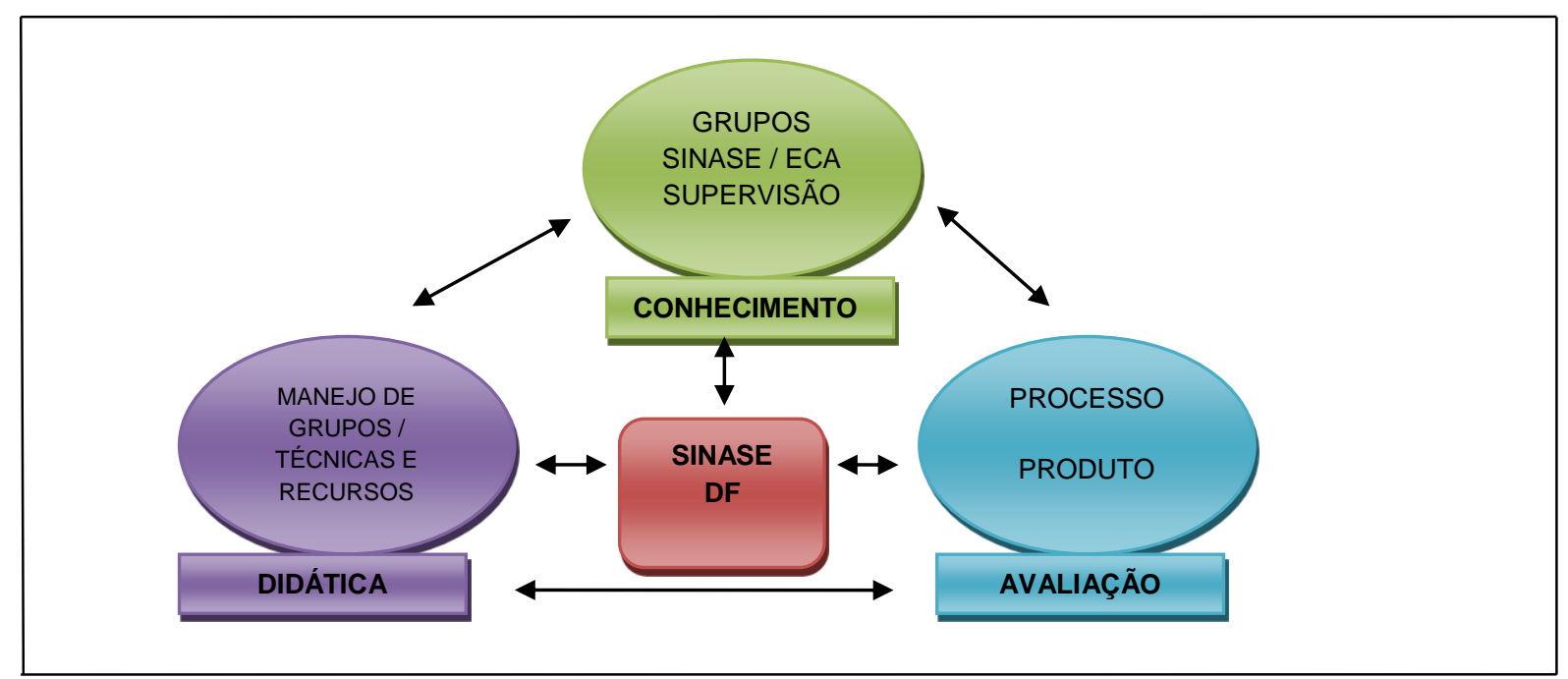

Fonte: 0 autor.

Observa-se diante dos relatos e das sugestões a necessidade de a Universidade atuar cada vez mais próxima da sociedade, contribuindo na geração de novas teorias e saberes científicos, e no aprimoramento e desenvolvimento de técnicas para o aperfeiçoamento das práticas destinadas a produção de novos conhecimentos, de recursos para o manejo com grupos e de processos avaliativos que permitam qualificar sistematicamente 0 desenvolvimento dos grupos socioeducativos. 


\section{CONSIDERAÇÕES FINAIS}

A pesquisa realizada junto aos profissionais que trabalham diretamente com adolescentes em cumprimento de medidas socioeducativas foi uma bela aventura a qual tive o privilégio vivenciar. Pude percorrer por diversos caminhos, lugares, e saberes que nem sempre convergiam, o que foi fantástico.

Conhecer realidades diferentes, ideias e conceitos acerca de grupos socioeducativos, me fez perceber que nem sempre existe uma coerência de entendimentos.

Antes de falar de grupos socioeducativos, precisamos entender a socioeducação e a quem ela se destina. Se invertemos o termo socioeducação para educação social, poderia perceber o grupo socioeducativo como grupos sociais reunidos com propósitos educativos e focados, por exemplo, na interação interpessoal, na participação social, na cidadania e no desenvolvimento social dos indivíduos.

Observo que o SINASE se apropriou do termo socioeducativo, entretanto acredito que não tenha exclusividade sobre ele. Acredito sim que as medidas socioeducativas são alguns dos espaços que se pode trabalhar a socioeducação.

A partir da análise dos dados coletados foi possível observar alguns dos alcances dos grupos socioeducativos realizados com adolescentes em cumprimento de medidas socioeducativas. Os principais benefícios citados pelos participantes, tanto das medidas em meio aberto, quanto das medidas de semiliberdade e de internação é estimular a interação social, compartilhar histórias de vida como também possibilidades de adquirir novos conhecimentos e saberes.

Quanto as limitações, atualmente estão associadas a falta de espaços apropriados, a carência de recursos humanos, e a ausência de padrões avaliativos institucionalizados o que pode dificultar análise qualitativa do desenvolvimento dos grupos socioeducativos.

Os grupos socioeducativos junto a adolescentes em cumprimento de medidas socioeducativas são terrenos férteis para a intervenção pedagógica qualificada. Para 
isso existe a necessidade das Universidades se apropriarem da socioeducação e contribuírem para a consolidação e ampliação de seus objetivos pedagógicos.

Na Faculdade de Educação da Universidade de Brasília, existe apenas dois projetos que trabalham na temática da socioeducação. O Grupo de Ensino-PesquisaExtensão em Educação Popular e Estudos Filosóficos e Histórico-Culturais GENPEX, que atualmente atua com duas frentes, sendo uma na região administrativa de Taguatinga DF, com foco em trabalhos e pesquisa na socioeducação, em parceira com uma Unidade de Semiliberdade e o Projeto 3, Círculo de Giz, que já completa 10 (dez) anos, mas que diz respeito a atuação em grupos socioeducativos com adultos e ao Artigo 28 da Lei de Drogas (Lei 11.343/2006).

Sugere-se a Faculdade de Educação ofertar aos estudantes mais disciplinas, estágios e projetos, nos eixos do ensino, pesquisa e extensão, voltadas para a socioeducação, para o conhecimento das legislações que tratam das medidas socioeducativas destinadas a adolescentes que pratiquem atos infracionais, e com isso possibilitar aos profissionais e a comunidade acadêmica aprimorar conhecimentos práticos, teóricos, didáticos e avaliativos, para assim aperfeiçoar e qualificar sistematicamente a teoria e a prática da pedagogia de grupos socioeducativos. 


\section{PERSPECTIVAS PROFISSIONAIS}

O tempo passa rápido, e quando a gente menos espera encerram-se alguns ciclos e se iniciam outros. A vida nos permite aprender e reaprender constantemente novos conhecimentos.

Acredito que os aprendizados que internalizei durante o tempo que frequentei a Faculdade de Educação como aluno do curso de Pedagogia, serão de grande importância para a minha prática profissional enquanto Educador Social da Secretaria de Estado de Políticas para Crianças Adolescentes e Juventude do Distrito Federal SECRIANÇA.

Trabalho desde 2014 com a socioeducação, diretamente com a medida socioeducativa de Internação, que é uma das medidas socioeducativas que podem ser aplicadas a adolescentes que pratiquem ato infracional, conforme preconiza o Estatuto da Criança e do Adolescente - ECA

Adoro o que faço e desde o começo da minha prática profissional sinto a constante necessidade de estudar. Sou grato por mais esta conquista alcançada, e pela certeza que esses aprendizados adquiridos durante curso de Pedagogia vão contribuir para qualificar ainda mais minhas práticas profissionais.

Pretendo iniciar mestrado acadêmico e continuar com meus objetivos de qualificação profissional na área da socioeducação, especificamente junto a medidas socioeducativas previstas no ECA. 


\section{REFERÊNCIAS}

AMORIM, Daniele Souza. As contribuições do pedagogo em um grupo socioeducativo. 2014. [59] f., il. Monografia de graduação. Faculdade de Educação da Universidade de Brasília, Brasília, 2014.

BABBIE, Earl. Métodos de Pesquisa de Survey. Belo Horizonte: Ed. UFMG, 1999.

BARDIN, Laurence. Análise de conteúdo. São Paulo: Edições 70, 2016

BAREICHA, Paulo. Grupo sócio-educativo (GS) em uma perspectiva socionômica. In: GHESTI-GALVÃO I.; ROQUE B. C. E. (Org.). A aplicação da lei em uma perspectiva interprofissional: direto, psicologia, psiquiatria, serviço social e ciências sociais na prática jurisdicional. Rio de Janeiro: Lúmen Júris, 2010. Cap. 4, p.527-541

BISINOTO, C.; Oliva, O. B. ; Arraes, J. ; Galli, C. Y. ; Amorim, G. ; Souza, L. A. . SOCIOEDUCAÇÃO: ORIGEM, SIGNIFICADO E IMPLICAÇÕES PARA O ATENDIMENTO SOCIOEDUCATIVO. Psicologia em Estudo (Online), v. 20, p. 575$585,2016$.

BRASIL. Lei no 12.594 de 18 de janeiro de 2012. Institui o Sistema Nacional de Atendimento Socioeducativo (SINASE). Disponível em: <http://www.planalto.gov.br/ccivil_03/_ato2011-2014/2012/lei/l12594.htm> Acesso em: 16 abr. 2017

BRASIL. Ministério da Educação. Conselho Nacional de Educação. Resolução $\mathrm{CNE} / \mathrm{CP}$ no 1, de 15 de maio de 2006. Institui as diretrizes curriculares nacionais para o curso de Pedagogia. Diário Oficial da República Federativa do Brasil, Brasília, DF, 16 mai. 2006, p. 11, Seção 1.

BRASIL. Lei Federal $n^{\circ}$ 8.069, de 13 de julho de 1990, Estatuto da Criança e do Adolescente - $\quad$ ECA. Disponível em: <http://www.planalto.gov.br/ccivil_03/leis/L8069.htm> Acesso em: 16 abr. 2017.

BRASIL. Constituição (1988). Constituição da República Federativa do Brasil. Brasília, DF: Senado Federal: Centro Gráfico, 1988. 292 p.

COSTA, Antônio Carlos Gomes da. Por uma política nacional de execução das medidas socioeducativas: conceitos e princípios norteadores. Brasília: Secretaria Especial dos Direitos Humanos da Presidência da República-SEDH/PR, 2004.

COSTA, Antônio Carlos Gomes da. Pedagogia da presença; da solidão ao encontro. Belo Horizonte: Modus Faciendi, 2001. 140 p. 2o ed.

COSTA, Antônio Carlos Gomes da. Aventura Pedagógica: Caminhos e descaminhos de uma ação educativa. Belo Horizonte. Modus Faciendi, 1999a.

COSTA, Antônio Carlos Gomes da. A presença da Pedagogia: Teoria e Pratica da ação socioeducativa. São Paulo: Global: Instituto Ayrton Senna, 1999b. 
CRESWELL, John W. Projeto de Pesquisa. Métodos Qualitativo, Quantitativo e Misto. 3. ed. - Porto Alegre: Artmed, 2010.

DELORS, J. Educação: um tesouro a descobrir. 2ed. São Paulo: Cortez. Brasília, DF: MEC/UNESCO, 2003.

DISTRITO FEDERAL (2017). Secretaria de Estado de Política para Crianças, Adolescentes e Juventude do Distrito Federal. O Manual Sociopsicopedagógico das Unidades de Internação do Sistema Socioeducativo do Distrito Federal. Disponível em: <http://www.crianca.df.gov.br/noticias/item/3360-secrian\%C3\%A7apublica-manual-sociopsicopedag\%C3\%B3gico-das-unidades-deinterna\%C3\%A7\%C3\%A3o.html> Acesso em 16 abr de 2017.

DISTRITO FEDERAL (2016a). Secretaria de Estado de Política para Crianças, Adolescentes e Juventude do Distrito Federal. I PLANO DECENAL DE ATENDIMENTO SOCIOEDUCATIVO DO DISTRITO FEDERAL - PDASE. Disponível em: < http://www.agenciabrasilia.df.gov.br/wp-conteudo/uploads/2016/06/10-planodecenal-de-atendimento-socioeducativo-do-df-pdase.pdf> Acesso em 16 abr de 2017.

DISTRITO FEDERAL (2016b). DECRETO № 37.896, DE 27 DE DEZEMBRO DE 2016. Aprova o Regimento Interno da Secretaria de Estado de Políticas para Crianças, Adolescentes e Juventude do Distrito Federal, publicado no Diário Oficial do Distrito Federal, № 244, do dia 28 de dezembro de 2016.

DISTRITO FEDERAL (2016c). Relatório de Gestão da Subsecretaria do Sistema Socioeducativo, do dia 28 de novembro de 2016, disponível em: <http://www.crianca.df.gov.br/images/SUBSIS/Relatório\%20de\%20Gestão\%20Subsi s\%20-\%202016.pdf> Acesso em 14 mai de 2017.

FREIRE, Paulo. Pedagogia do oprimido. 54. ed. res. e atual. Rio de Janeiro: Paz e Terra, 2013.

LIBÂNEO, José Carlos. Pedagogia e Pedagogos, para quê? São Paulo: Cortez. 1988.

OLIVEIRA, Eliana de et al. Análise de conteúdo e pesquisa na área da educação. Revista Diálogo Educacional, Curitiba, v. 4, n. 9, p. 11-27, 2003.

SALIBA, Maurício Gonçalves. A educação como disfarce e vigilância: análise das estratégias de aplicação de medidas sócio-educativas a jovens infratores. 2006. Tese (Doutorado em Educação). UNESP, Marília, 2006.

ZANELLA, Andréa Vieira; PEREIRA, Renata Susan. Constituir-se enquanto grupo: a ação de sujeitos na produção do coletivo. Estudos de psicologia, v. 6, n. 1, p. 105$114,2001$. 
APÊNDICES 


\section{APENDICE A - ROTEIRO DE ENTREVISTA SEMIESTRUTURADO PARA OS ESPECIALISTAS SOCIOEDUCATIVOS}

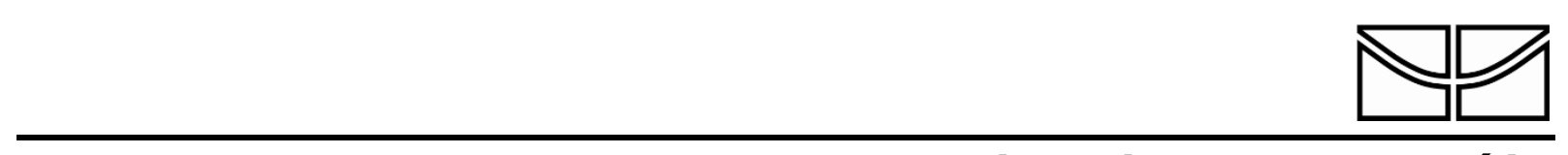

Universidade de Brasília

Faculdade de Educação

\section{ROTEIRO DE ENTREVISTA}

1.CARACTERIZAÇÃO DO RESPONDENTE

1.1.Genero: ( ) Masculino ( ) Feminino ( ) Outro

1.2.Idade: . Tempo de Experiência em Grupos Socioeducativos:

1.3.Cargo: ( ) Psicologo. ( ) Assistente Social. ( ) Pedagogo.

( ) Outro. Especifique:

1.4.Unidade de Lotação: ( ) UAMA （ ) SEMILIBERDADE ( ) INTERNAÇÃO

1.5.Local:

\subsection{ATENDIMENTO EM GRUPOS}

\subsection{Como são organizados os grupos para o atendimento socioeducativo?}

1) forma (entrevistas, dinâmicas, prontuário etc), 2) motivos (histórico de violência, uso de drogas, periculosidade, idade etc) da seleção de pessoas; 3) número de pessoas por grupo (porque?); 4) espaço físico dos atendimentos (sala, pátio, auditório, ar livre etc),

2.2. Os temas abordados são escolhidos previamente ou emergem do grupo? Exemplifique e descreva uma situação típica de atendimento.

(são temas que a Medida Socioeducativa requer - como tráfico, violência doméstica, escolarização, etc; ou são temas propostos pelos participantes conforme seu dia/aquecimento?)

\section{AVALIAÇÃO DOS ATENDIMENTOS}

3.1. Como são avaliados os atendimentos em grupo? (1 - critérios de avaliação da sessão e do conjunto de encontros; 2 - participação, motivação, implicação nas atividades; 3 - há alguma avaliação de um supervisor em questionário próprio?)

\section{CONCEITUAÇÃO}

\subsection{Quais os referenciais teórico-metodológicos adotados?}

1)Teorias de grupo (Gestalt, Psicodrama, Comportamental, Centrada na Pessoa, Psicodinâmica, Paulo Freire, Sócio-Histórica etc); 2) Principais autores/livros referência; 3) Principais recursos / técnicas utilizadas (filmes, colagens, contação de história, jornal vivo, dinâmicas de grupo, sociodramas, teatro, fantoches, palestras, rodas de conversa etc);

4.2. Como você define um Grupo Socioeducativo? (1 - o conceito, a natureza, a função e o papel de um grupo socioeducativo. 2 - Referir natureza multiprofissional e multireferencial do GS;).

4.3. Qual a sua sugestão para a Universidade melhorar a formação para atendimento de GS? 


\title{
APENDICE B - TERMO DE CONSENTIMENTO LIVRE E ESCLARECIDO
}

\author{
TERMO DE CONSENTIMENTO LIVRE E ESCLARECIDO
}

Eu aceito participar da pesquisa, intitulada "Alcance e limites da pedagogia de grupos realizada com adolescentes em cumprimento de medidas socioeducativas no Distrito Federal". O procedimento implica na realização de entrevistas semiestruturadas com servidores especialistas socioeducativos que atuam nas Unidades de Atendimento em Meio Aberto (UAMA's), nas Unidades de Semiliberdade (US) e nas Unidades de Internação (UI). A pesquisa será desenvolvida pelo graduando em Pedagogia Aurélio Landim Albuquerque, sob orientação da Professor Doutor Paulo Bareicha, professor adjunto da Faculdade de Educação da Universidade de Brasília - UnB.

Estou ciente do tema e dos objetivos deste estudo, bem como das normas éticas que garantem: (a) o total sigilo das identidades pessoais dos participantes desta pesquisa; (b) que a participação é voluntária e os participantes podem se desligar a qualquer momento da pesquisa ou não responder alguma pergunta específica quando desejar, sem que isto acarrete nenhum tipo de prejuízo.

Em caso de concordância com as considerações expostas, solicitamos que assine este "Termo de Consentimento Livre e Esclarecido" no local indicado abaixo. Desde já agradecemos sua colaboração e nos comprometemos com a disponibilização dos resultados obtidos nesta pesquisa, tornando-os acessíveis a todos os participantes.

Brasília, de de 2017.

Assinatura

Aurélio Landim Albuquerque (matrícula 15/0155972)

PAULO BAREICHA

Professor Adjunto FE-UNB

Mat. 147702 


\title{
APENDICE C - SOLICITAÇÃO DE AUTORIZAÇÃO JUDICIAL
}

\section{Universidade de Brasília Faculdade de Educação}

\author{
A: Sua Excelência a Senhora \\ Juíza LAVÍNIA TUPY VIEIRA FONSECA \\ Titular da Vara de Execução de Medidas Socioeducativas do Distrito Federal \\ SGAN 909 Lotes D/E \\ 70.760-090 \\ De: Professor Dr. Paulo Bareicha \\ Faculdade de Educação da Universidade de Brasília
}

Assunto: Solicitação de autorização para realização de pesquisa junto a servidores que atuam em medidas socioeducativas

Senhora Juíza,

Desde 2007 temos realizado pesquisa-ação em parceria com o TJDFT (SERUC, Fórum Leal Fagundes), que nos encaminha jurisdicionados do artigo 28 da lei 11.343/2006 (lei de drogas), realizando grupos socioeducativos (GS). Os principais resultados acadêmicos dizem respeito a dissertações de mestrado, monografias de graduação e artigos científicos produzidos sobre o tema de GS. Para conhecimento em anexo encaminho artigo explicativo publicado em livro lançado no $1^{\circ}$ Congresso Internacional Psicossocial Jurídico, em 2010.

O objetivo desta solicitação é demandar autorização necessária para a realização de pesquisa junto aos servidores da SECRIA que realizam Grupos Socioeducativos com adolescentes acompanhados pela VEMSE.

A pesquisa que queremos realizar é intitulada "Alcance e limites da pedagogia de grupos realizada com adolescentes em cumprimento de medidas socioeducativas no Distrito Federal". O procedimento implica a realização de entrevistas semiestruturadas com servidores especialistas socioeducativos que atuam nas Unidades de Atendimento em Meio Aberto (UAMA), nas Unidades de Semiliberdade (US) e nas Unidades de Internação (UI). Serão abordadas questões relativas aos grupos socioeducativos que são realizados, suas concepções teóricas e metodológicas, seu suporte referencial, o tipo de formação requerido, as metas da abordagem, as razões para o alcance ou não dos objetivos propostos. A pesquisa não contemplará qualquer dado sigiloso dos adolescentes. Um resumo do Projeto dessa Pesquisa também é apresentado em anexo.

Sob minha orientação (Paulo Sergio de Andrade Bareicha), o aluno Aurélio Landim Albuquerque matrícula 15/0155972, desenvolverá o procedimento de coleta de dados. Esperamos com os resultados alcançados fomentar a discussão a respeito da natureza e da importância da formação socioeducativa oferecida nos cursos superiores, em particular, no curso de Pedagogia.

Respeitosamente subscrevo-me,

PAULO BAREICHA

Professor Adjunto FE - UNB 